\title{
The role of imaging in pulmonary hypertension
}

\author{
Meenal Sharma ${ }^{1}$, Andrew T. Burns ${ }^{1}$, Kelvin Yap $^{1}$, David L. Prior ${ }^{1,2}$ \\ ${ }^{1}$ Department of Cardiology, St Vincent's Hospital Melbourne, Fitzroy, Australia; ${ }^{2}$ Department of Medicine, The University of Melbourne at St \\ Vincent's Hospital (Melbourne), Melbourne, Australia \\ Contributions: (I) Conception and design: All authors; (II) Administrative support: None; (III) Provision of study materials or patients: None; (IV) \\ Collection and assembly of data: All authors; (V) Data analysis and interpretation: All authors; (VI) Manuscript writing: All authors; (VII) Final \\ approval of manuscript: All authors. \\ Correspondence to: Prof David L. Prior. Department of Cardiology, St Vincent's Hospital, 41 Victoria Pde, Fitzroy 3161, Australia. \\ Email: david.prior@svha.org.au.
}

\begin{abstract}
Pulmonary hypertension $(\mathrm{PH})$ is a debilitating and potentially life threatening condition in which increased pressure in the pulmonary arteries may result from a variety of pathological processes. These can include disease primarily involving the pulmonary vasculature, but more commonly $\mathrm{PH}$ may result from left-sided heart disease, including valvular heart disease. Chronic thromboembolic pulmonary hypertension (CTEPH) is an important disease to identify because it may be amenable to surgical pulmonary artery endarterectomy or balloon pulmonary angioplasty. Parenchymal lung diseases are also widespread in the community. Any of these disease processes may result in adverse remodeling of the right ventricle and progressive right heart (RH) failure as a common final pathway. Because of the breadth of pathological processes which cause $\mathrm{PH}$, multiple imaging modalities play vital roles in ensuring accurate diagnosis and classification, which will lead to application of the most appropriate therapy. Multimodality imaging may also provide important prognostic information and has a role in the assessment of response to therapies which ultimately dictate clinical outcomes. This review provides an overview of the wide variety of established imaging techniques currently in use, but also examines many of the novel imaging techniques which may be increasingly utilized in the future to guide comprehensive care of patients with $\mathrm{PH}$.
\end{abstract}

Keywords: Pulmonary hypertension (PH); right ventricle; multimodality imaging; echocardiography; computed tomography; cardiac magnetic resonance

Submitted Feb 26, 2020. Accepted for publication Jul 17, 2020.

doi: $10.21037 / \mathrm{cdt}-20-295$

View this article at: http://dx.doi.org/10.21037/cdt-20-295

\section{Introduction}

The right ventricular (RV)-pulmonary circulation complex normally functions at significantly lower pressures than the systemic circulation. Pulmonary hypertension ( $\mathrm{PH})$ is the presence of elevated pulmonary arterial pressure, arising from a number of different pathologies. The 6th World Symposium on PH task force in 2018 proposed a new hemodynamic definition of PH (1). Normal mean pulmonary artery pressure (mPAP) at rest is now defined as $14.0 \pm 3.3 \mathrm{mmHg}(2)$. This has resulted in the universally accepted threshold for an abnormal mPAP being set to $>20 \mathrm{mmHg}$, the previous threshold for an abnormal hemodynamic mPAP was $\geq 25 \mathrm{mmHg}$ (3). Importantly, this new threshold for an abnormal mPAP is not specific for primary pulmonary vascular disease, as mPAP is dependent on cardiac output and pulmonary artery wedge pressure (PAWP) and PH may result from a number of pathologies (4). Accordingly, $\mathrm{PH}$ is categorised according to the pattern of hemodynamic abnormality and the underlying aetiology.

Hemodynamically, $\mathrm{PH}$ is classified into pre-capillary $\mathrm{PH}$, post capillary $\mathrm{PH}$ and combined pre- and postcapillary PH (Table 1). In addition to mPAP (threshold of $>20 \mathrm{mmHg}$ ), this classification takes into account the PAWP and the pulmonary arterial vasculature, reflected by pulmonary vascular resistance (PVR) with a threshold of 3 
Table 1 Updated hemodynamic definition of pulmonary hypertension $(\mathrm{PH})$

\begin{tabular}{lc}
\hline Definitions & Characteristics \\
\hline Pre-Capillary PH & mPAP $>20 \mathrm{mmHg}$ \\
& PAWP $\leq 15 \mathrm{mmHg}$ \\
& PVR $\geq 3$ Wood units \\
Isolated Post-Capillary PH & mPAP $>20 \mathrm{mmHg}$ \\
& PAWP $>15 \mathrm{mmHg}$ \\
Combined Pre- and Post-Capillary PH & PVR $<3$ Wood units \\
& PAWP $>15 \mathrm{mmHg}$ \\
& PVR $\geq 3$ Wood units \\
\hline
\end{tabular}

mPAP, mean pulmonary artery pressure; PAWP, pulmonary artery wedge pressure; PVR, pulmonary vascular resistance.

\section{Wood Units (1).}

The new threshold mPAP for $\mathrm{PH}$ demonstrates improved correlation with clinical outcomes across the different subgroups of $\mathrm{PH}$ (5-11), ensuring that patients below the previously defined hemodynamic threshold are not subject to delayed diagnosis and initiation of lifesaving therapy. Once a diagnosis of $\mathrm{PH}$ is suspected, it is imperative to identify the underlying etiology of PH. The World Health Organisation (WHO) classification endeavours to simplify this, by dividing $\mathrm{PH}$ into five pathophysiological subgroups, as was described and expanded upon by Simonneau et al. (12) (Table 2). Although hemodynamic diagnosis is based on invasive right heart $(\mathrm{RH})$ catheterisation, imaging plays an important role in the identification and classification of $\mathrm{PH}$, enabling earlier diagnosis and management of $\mathrm{PH}$ that in turn leads to improved long term outcomes for patients (13-15).

\section{The current role of imaging in the evaluation of PH}

Non-invasive imaging of the heart is a key tenet in the identification of $\mathrm{PH}$ through evaluation of $\mathrm{RH}$ pressures, $\mathrm{RV}$ morphology and function and assessment of the left heart. Additional imaging techniques that evaluate the lung parenchyma and vasculature assist with classification. The ultimate goal of all imaging techniques is to diagnose $\mathrm{PH}$, accurately identify the etiology and stratify risk. The advent of multimodality imaging has enabled earlier diagnosis and reduced the need for invasive hemodynamic measurements of $\mathrm{RH}$ pressures, mitigating associated procedural risk.

$\mathrm{RV}$ dysfunction and subsequent failure is the main predictor of adverse outcomes and the most common cause of death in patients with pulmonary arterial hypertension (PAH) (16-20). Accurate and reproducible assessment of the right ventricle is therefore paramount, albeit challenging, due to the complex geometry and load dependence of the right ventricle (21). Complementary imaging techniques are often utilised to obtain structural and functional information of the right ventricle, providing incremental information that the clinician must use to guide management decisions.

This review provides an overview and summary of current and novel non-invasive imaging techniques used to evaluate RV morphology, function, flow and tissue characterisation, in addition to the critical roles of imaging in identifying associated cardiac and pulmonary findings which provide both diagnostic and prognostic information. The advantages and limitations of these imaging modalities will also be highlighted, particularly in the context of application to the assessment and management of $\mathrm{PH}$.

\section{Chest radiograph (CXR)}

The CXR is often the initial investigation in the evaluation of a patient with shortness of breath or other symptoms suggestive of $\mathrm{PH}$. It garners widespread use due to the relative ease of access and low cost. The CXR may provide clues both to the presence of $\mathrm{PH}$ and also the underlying cause. In patients with $\mathrm{PAH}$, findings may include: (I) dilatation of the main and central pulmonary arteries i.e., right interlobar pulmonary artery $>16 \mathrm{~mm}$ in men and $>15 \mathrm{~mm}$ in women (22) (Figure 1); (II) tapering of the peripheral and branch pulmonary arteries commonly referred to as "pruning" $(23,24)$ (Figure 1); (III) increased ratio of pulmonary artery to pulmonary vein (25). CXR features suggestive of group $2 \mathrm{PH}$ may include cardiomegaly with enlargement of the left-sided chambers, valve calcification and pulmonary venous congestion. In group $3 \mathrm{PH}$, the CXR may reveal lung parenchymal pathology such as interstitial fibrosis, bronchiectatic changes (Figure 2) or extensive emphysema.

In rare cases, patients with Group $4 \mathrm{PH}$, i.e., patients with chronic thromboembolic pulmonary hypertension (CTEPH), due to large emboli, the CXR may reveal a Hampton's Hump (26) (a wedge-shaped opacification secondary to pulmonary infarction) or Westermark's Sign (an area of pulmonary oligemia) (27). Both are exceedingly rare signs and more often the findings on CXR in CTEPH 
Table 2 Updated classification of pulmonary hypertension

1. Pulmonary arterial hypertension $(\mathrm{PAH})$

1.1 Idiopathic PAH

1.2 Heritable PAH

1.3 Drug and toxin induced

1.4 Associated with:

1.4.1 Connective tissue disease

1.4.2 HIV infection

1.4.3 Portal hypertension

1.4.4 Congenital heart diseases

1.4.5 Schistosomiasis

1.5 $\mathrm{PAH}$ long term responders to calcium channel blockers

1.6 PAH with overt features of venous/capillary involvement (PVOD)

1.7 Persistent $\mathrm{PH}$ of the newborn syndrome

2. Pulmonary hypertension due to left heart disease

2.1 $\mathrm{PH}$ due to heart failure with preserved LVEF

2.2 $\mathrm{PH}$ due to heart failure with reduced LVEF

2.3 Valvular disease

2.4 Congenital/acquired left heart inflow/outflow tract obstruction and congenital cardiomyopathies

3. Pulmonary hypertension due to lung diseases and/or hypoxia

3.1 Chronic obstructive pulmonary disease

3.2 Restrictive lung disease

3.3 Other pulmonary diseases with mixed restrictive and obstructive pattern

3.4 Hypoxia without lung disease

3.5 Developmental lung diseases

4. Chronic thromboembolic pulmonary hypertension (CTEPH)

5. Pulmonary hypertension with unclear multifactorial mechanisms

5.1 Hematologic disorders: chronic hemolytic anemia, myeloproliferative disorders, splenectomy

5.2 Systemic disorders: sarcoidosis, pulmonary histiocytosis, lymphangioleiomyomatosis

5.3 Others

5.4 Complex congenital heart disease

Adapted from Simonneau G, Robbins IM, Beghetti M, et al. Updated clinical classification of pulmonary hypertension. J Am Coll Cardiol 2009;54:S43-54. Reproduced with permission of the C) ERS 2020: European Respiratory Journal 53 (1) 1801913; DOI: 10.1183/13993003.01913-2018 Published 24 January 2019. HIV, human immunodeficiency virus; PVOD, pulmonary veno-occlusive disease; LVEF, left ventricular ejection fraction. 


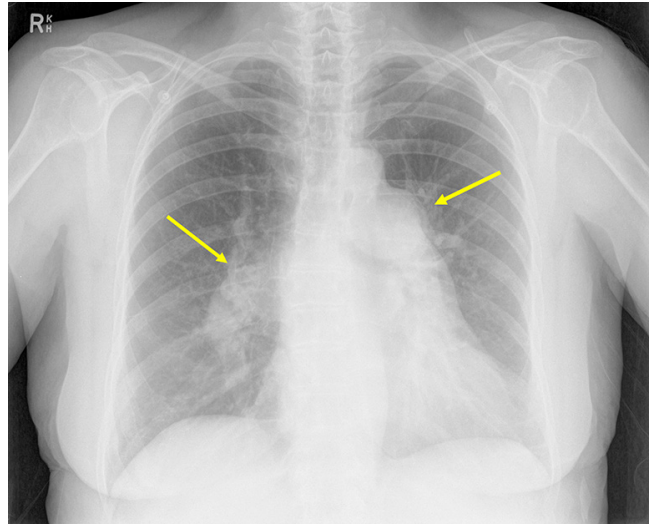

Figure 1 AP frontal radiograph in a 55-year-old female with pulmonary arterial hypertension demonstrating markedly prominent pulmonary arteries (arrows) and peripheral arterial pruning.

are non-specific. Right sided chamber remodelling due to chronic PH may also be seen on a CXR. Right atrial enlargement can be seen on the postero-anterior projection. In the lateral projection, cavity obliteration of the retrosternal space may be seen due to RV enlargement.

\section{Echocardiography}

\section{Transthoracic echocardiography (TTE)}

TTE and Doppler imaging provide a direct, non-invasive and reproducible assessment of $\mathrm{RH}$ morphology, function and hemodynamics. It is the screening investigation of choice in the workup of all patients with suspected $\mathrm{PH}$, reflected in all clinical practice guidelines (3). Furthermore, it enables the assessment of potential left heart causes of $\mathrm{PH}$ including valvular disease, LV systolic or diastolic dysfunction, congenital heart disease and the presence of intracardiac shunts (28).

Commonly accepted thresholds for morphological, functional and non-invasive estimation of $\mathrm{RH}$ hemodynamics are listed in Table 3.

These parameters reflect mechanical coupling and uncoupling between the right ventricle and pulmonary artery, with contribution from left ventricular contraction. (3,39-43).

\section{Hemodynamic assessment using echocardiography}

TTE has long been the primary method of non-invasive hemodynamic screening and assessment of symptomatic patients. Pulmonary artery systolic pressure (PASP), in

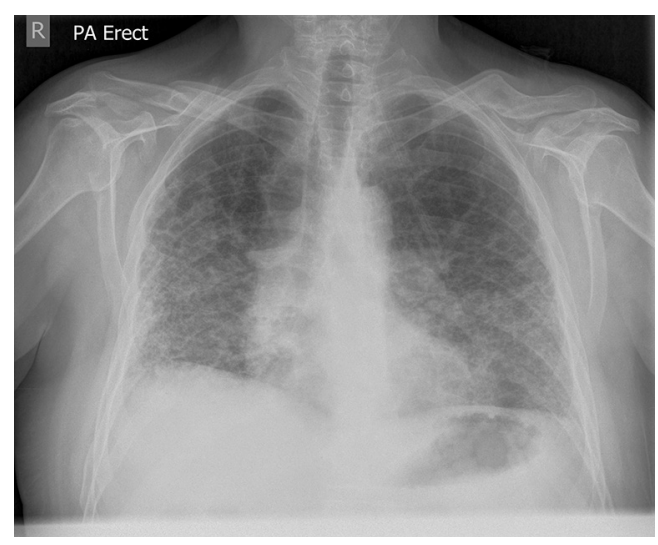

Figure 2 PA chest radiograph in a 62-year-old male demonstrating extensive middle and lower zone pulmonary fibrosis.

the absence of RV outflow obstruction, is equivalent to the right ventricular systolic pressure (RVSP). The RVSP is calculated using the peak tricuspid valve regurgitant velocity and adding the right atrial pressure. Tricuspid valve velocity is measuring using continuous wave Doppler of the tricuspid regurgitant jet (Figure 3A,B). The modified Bernoulli equation is then used to calculate the pressure gradient across the tricuspid valve as depicted in the formula below (44).

$$
\Delta \mathrm{P}=4 \mathrm{v}^{2}
$$

To calculate the PASP, the pressure of the right atrium (RAP) must be added to the Bernoulli equation derived trans-tricuspid pressure. As per the American Society of Echocardiography (ASE) guidelines, the linear dimension and collapsibility of the inferior vena cava is used to estimate the RAP (44) (Figure 3C,D). A dilated IVC which does not collapse $>50 \%$ of its initial size with a sniff indicates elevated RA pressure of $15 \mathrm{mmHg}$.

In the absence of an accurately measurable or undetectable TR jet, pulmonary artery acceleration time less than $90 \mathrm{~ms}$, mid-systolic notching of the pulmonary valve pulsed wave Doppler signal, early diastolic pulmonary regurgitation velocity $>2.2 \mathrm{~m} / \mathrm{s}$ (Figure $4 A$ ), mean PAP measurement calculated from end diastolic pulmonary regurgitant jet velocity (Figure $4 B$ ) and flattening of the interventricular septum throughout the cardiac cycle (Figure 5), are additional parameters suggestive of $\mathrm{PH}(44)$.

\section{Left heart assessment on echo}

As left heart disease (group $2 \mathrm{PH}$ ) is the most common cause of $\mathrm{PH}$ (45), mediated through chronic elevation 
Table 3 Commonly used transthoracic echocardiogram measurements in the assessment of pulmonary hypertension

\begin{tabular}{|c|c|c|}
\hline Measurement & Accepted Abnormal Threshold & Significance of threshold \\
\hline Right atrial area & $>20 \mathrm{~cm}^{2}$ & $>27 \mathrm{~cm}^{2}$ predicts need for transplant (29) \\
\hline Indexed right atrial area & $>5 \mathrm{~cm}^{2} / \mathrm{m}$ & Predictor of mortality (30) \\
\hline \multirow[t]{2}{*}{ RV dimensions } & RV Base $>42 \mathrm{~mm}$ & (31) \\
\hline & RV End Diastolic Area & $\begin{array}{l}\text { Used to calculate the biventricular index which be associated with } \\
\text { increased mortality (32) }\end{array}$ \\
\hline RV fractional area change & $<35 \%$ & Predictor of adverse outcomes (33-35) \\
\hline RV longitudinal strain & Reduced strain values & Predictor of poor outcomes $(36-38)$ \\
\hline \multirow[t]{2}{*}{ Pericardial effusion } & \multirow[t]{2}{*}{ Present } & Correlates with right atrial pressure \\
\hline & & Predictor of prognosis $(13,30)$ \\
\hline \multicolumn{3}{|l|}{ Hemodynamic parameters } \\
\hline \multirow{2}{*}{$\begin{array}{l}\text { Peak velocity of tricuspid } \\
\text { regurgitation }\end{array}$} & $>3.4 \mathrm{~m} / \mathrm{s}$ & Sensitive predictor of sPAP $>50 \mathrm{~mm} \mathrm{Hg}$ \\
\hline & $>2.9 \mathrm{~m} / \mathrm{s}$ & Sensitive predictor of sPAP $>40 \mathrm{~mm} \mathrm{Hg}$ \\
\hline $\begin{array}{l}\text { Peak diastolic pulmonary } \\
\text { regurgitation jet velocity }\end{array}$ & $>2.2 \mathrm{~m} / \mathrm{s}$ & Sensitive predictor of mean pulmonary artery pressure $>16 \mathrm{mmHg}$ \\
\hline \multirow[t]{2}{*}{ IVC distensibility } & $<50 \%$ collapsibility & Indicative of elevated right atrial pressure (RAP) (30) \\
\hline & $>2.1 \mathrm{~cm}$ & Elevated RAP predicts worse outcomes (16) \\
\hline
\end{tabular}

sPAP, systolic pulmonary artery pressure; RV, right ventricular; PVR, pulmonary vascular resistance.

of left atrial pressure, a thorough assessment of the left heart is critical in the assessment of any patient with $\mathrm{PH}$. This will include assessment of left ventricular structure, systolic function and diastolic function including assessment of filling pressures. Identification of left sided valve disease, particularly mitral valve disease as a cause of $\mathrm{PH}$ is important. Correction of valve disease may reduce pulmonary artery pressure. In addition, the presence of $\mathrm{PH}$ may impact prognosis even after correction of valve abnormalities. Both mitral stenosis (Figure $6 A$ ) and mitral regurgitation (Figure 6B) may lead to chronically elevated LA pressure and subsequent $\mathrm{PH}$. Although this is usually isolated post-capillary $\mathrm{PH}$ in the early stages, chronic elevation may result in combined pre- and postcapillary PH. Finally, the presence of $\mathrm{PH}$ in patient with heart failure with reduced ejection fraction (HFREF) is associated with worsening of prognosis (46).

\section{Structural assessment of the RH using echo}

Morphology and size of the RH are assessed on B-mode 

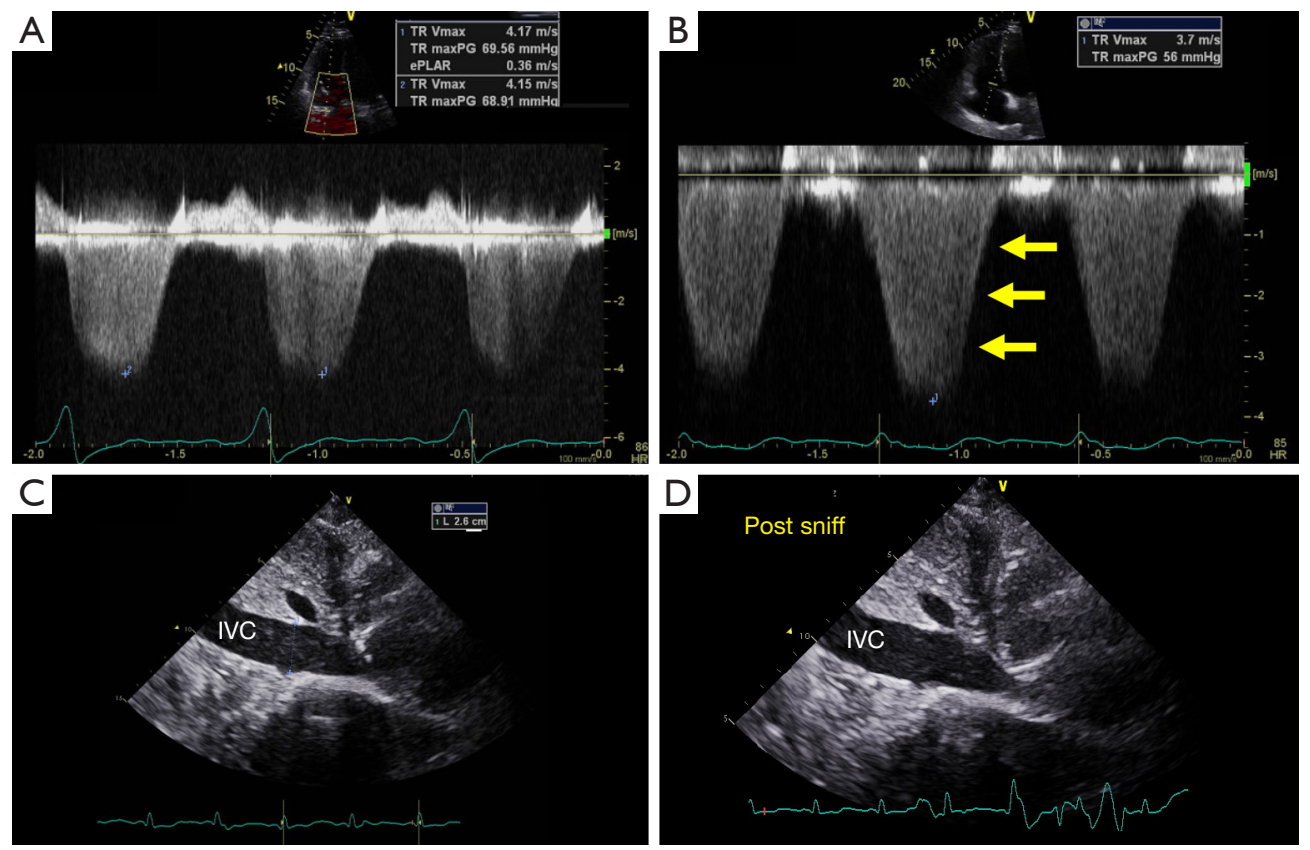

Figure 3 Estimation of pulmonary artery systolic pressure from the peak tricuspid regurgitation continuous wave Doppler velocity (A,B) and from the size of the inferior vena cava and its response to a sniff (C,D). The IVC size fails to decrease with a sniff indicting elevated right atrial pressure.
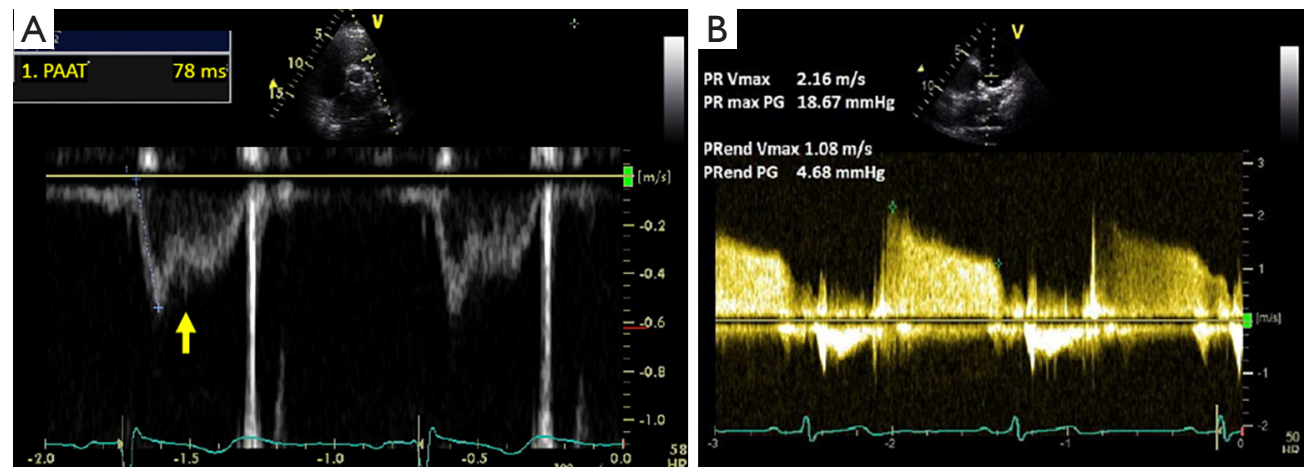

Figure 4 Doppler features supporting the presence of pulmonary hypertension (PH). A short pulmonary artery acceleration time (PAAT) $<90 \mathrm{~ms}$ and the presence of mid-systolic notching (arrow) of the pulmonary valve pulsed wave Doppler signal (A) suggest PH. Using a CW Doppler recording of the pulmonary regurgitation (PR) signal, the PR Vmax can be used to estimate the mean pulmonary artery (PA) pressure and the PR diastolic pressure estimated from the end-diastolic velocity (B).

with 2D linear and volumetric assessment (Figure 7). Right atrial size can be quantified in terms of area $\left(\mathrm{cm}^{2}\right)$ or indexed volume $\left(\mathrm{mL} / \mathrm{m}^{2}\right)$ and provides important prognostic information. TTE characteristics in patients with $\mathrm{PH}$ include flattening of the intraventricular septum throughout the cardiac cycle, but particularly at endsystole, which is indicative of pressure overload (Figure 5).
Conversely, a volume loaded right ventricle will result in flattening of the septum during diastole. This can be objectively assessed by using the $\mathrm{LV}$ eccentricity index, a ratio of the diameter perpendicular to the interventicular septum and the diameter perpendicular to this line. An LV diastolic eccentricity index of $>1.7$ has been shown to predict mortality in patients with $\mathrm{PH}$ (30). Other echo 


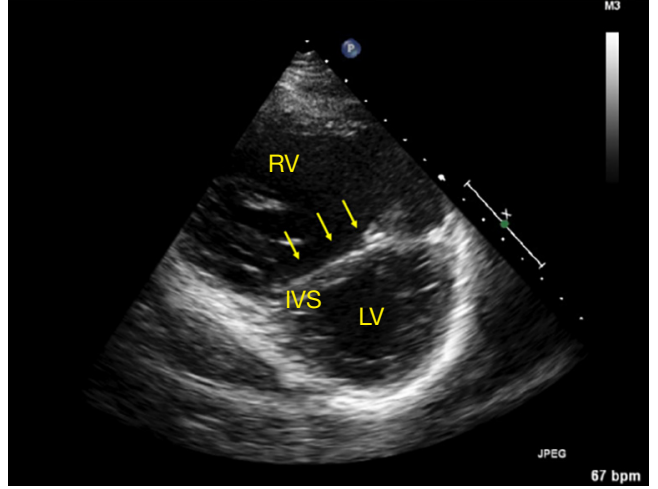

Figure 5 Parasternal short axis view of the heart showing a dilated right ventricle (RV) and a flattened interventricular septum (IVS, arrows) resulting in a D-shaped left ventricle (LV) due to $\mathrm{RV}$ pressure overload. features of $\mathrm{PH}$ include $\mathrm{RV}$ free wall hypertrophy (free wall thickness $>5 \mathrm{~mm}$ ) and bowing of the interatrial septum into the left atrium during diastole. As $\mathrm{PH}$ progresses, there is often RV dilatation. $\mathrm{RV}$ dimensions are routinely measured in an RV focused apical 4 chamber view with abnormal cutoffs being defined as $>42 \mathrm{~mm} \mathrm{RV}$ base and $>35 \mathrm{~mm} \mathrm{RV}$ mid wall. The biventricular index, which compares the RV end diastolic area to the LV end diastolic area, has been shown to be associated with increased mortality in patients with $\mathrm{PH}$ (32). The presence of a pericardial effusion is an independent predictor of mortality in $\mathrm{PH}$ patients and is thought to reflect underlying raised right atrial pressures. Serial transthoracic echocardiogram can be used to evaluate for the persistence of an effusion and measure the size of the effusion $(13,16,47)$.
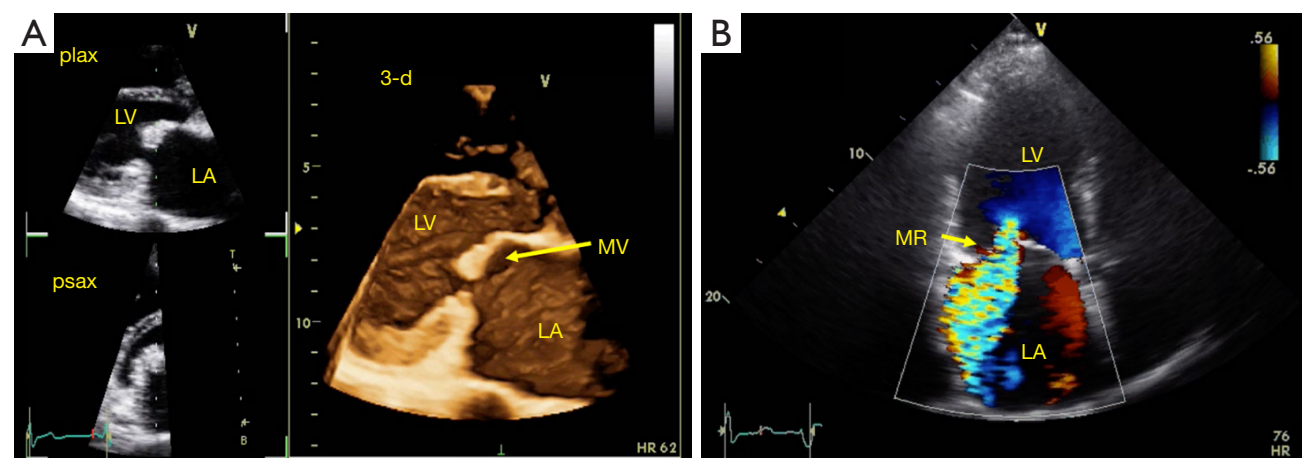

Figure 6 Mitral valve disease may cause pulmonary hypertension. (A) Transthoracic echocardiogram showing rheumatic mitral stenosis including a rendered 3-d image with diastolic doming of the anterior mitral valve (MV) leaflet; (B) severe mitral regurgitation (MR). LV, left ventricle; LA left atrium; plax, parasternal long axis; psax, parasternal short axis.
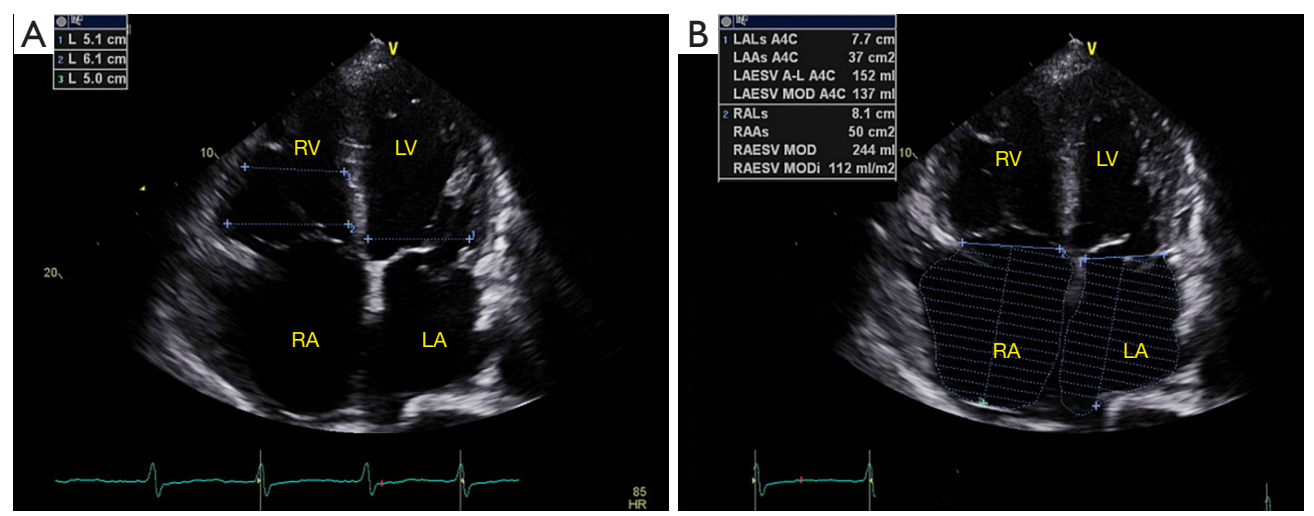

Figure 7 Assessment of right heart size by echocardiography. (A) Measurement of right ventricular diameter from an apical 4-chamber view; (B) measurement of right atrial area from an apical 4-chamber view. RV, right ventricle; RA, right atrium; LV, left ventricle; LA, left atrium. 

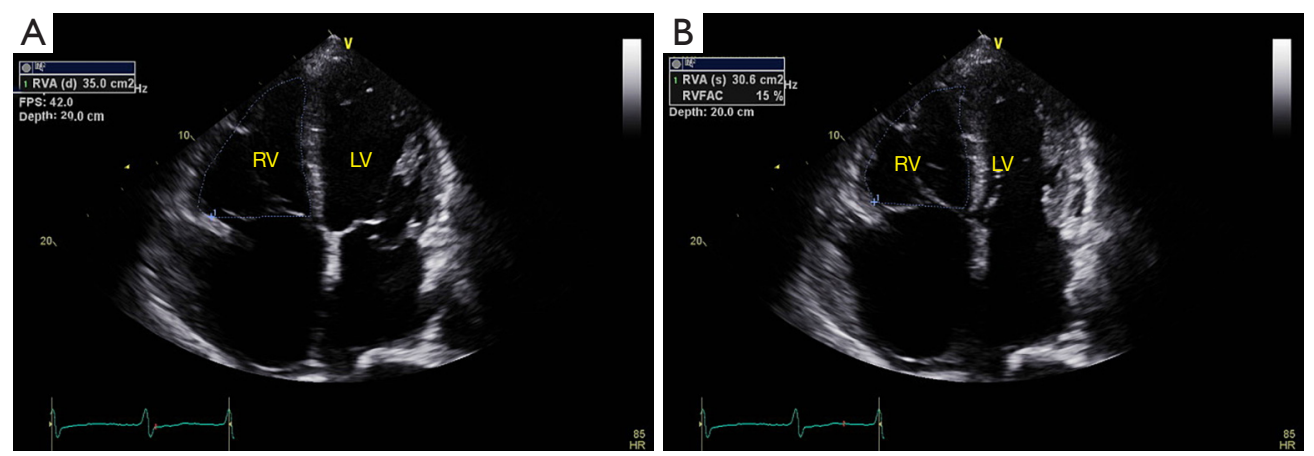

Figure 8 Quantification right heart systolic function using fractional area change (FAC). The area of the right ventricle is measured at enddiastole (A) and end-systole (B) and the percentage area change is the FAC. FAC is decreased in this example. RV, right ventricle; LV, left ventricle.
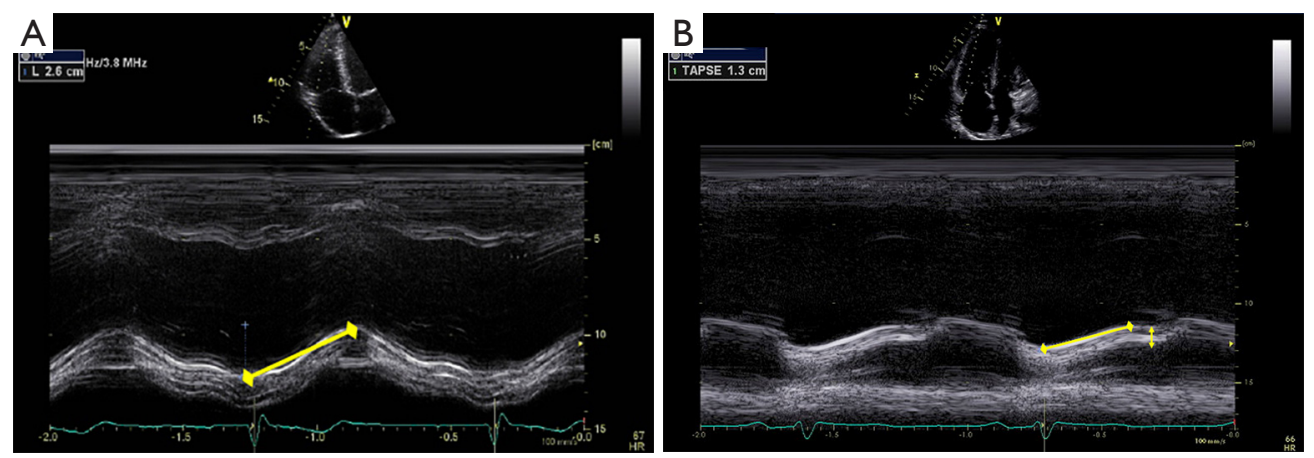

Figure 9 Measurement of tricuspid annular plane systolic excursion (TAPSE) in a normal subject (A) and in a patient with pulmonary hypertension (B) where TAPSE is reduced.

\section{RV systolic function assessment using echo}

RV systolic function can be assessed on echo using multiple parameters including RV ejection fraction (RVEF) RV fractional area change (FAC), tricuspid annular plane systolic excursion (TAPSE), RV S', RV myocardial performance index and strain. RV FAC (\%), measures the difference between end diastolic and end systolic area divided by end diastolic area to assess RV systolic function (Figure 8).

M-mode, with its high temporal resolution is used to measure the excursion of the tricuspid annulus in the longitudinal plane during systole (TAPSE). This is a reproducible measure of $\mathrm{RV}$ function along the primary axis of contraction and is used to track response to therapy (Figure 9). TAPSE correlates directly with prognosis in the $\mathrm{PH}$ and left ventricular dysfunction cohort. However, it may remain falsely normal in patients with significant RV dysfunction in advanced $\mathrm{PH}$ when the dilated RV pivots around the LV apex in a rocking motion. Similarly, the peak
RV systolic annular velocity (RV S') is a tissue Doppler derived method used to quantify the velocity of systolic longitudinal movement of the lateral tricuspid annulus as a surrogate of function. Both TAPSE and RV S' have been shown to have prognostic value in $\mathrm{PH}$ (48) (Figure 10).

The RV myocardial performance index or Tei index is derived using Doppler assessment of tricuspid inflow. It is the addition of isovolumic contraction and relaxation time divided by the ejection time and is a surrogate for global RV function (49). Abnormal values are associated with worse prognosis in pre-capillary $\mathrm{PH}$ (33).

Finally, strain imaging utilising either tissue Doppler or speckle tracking may be used to quantitatively evaluate RV systolic function (50) (Figure 11). Reduced systolic longitudinal strain of the basal RV free wall has been shown to predict worse outcomes (51).

In practice, at least two of the aforementioned measures are routinely performed to enable robust and reproducible assessment of right sided function and minimise operator 

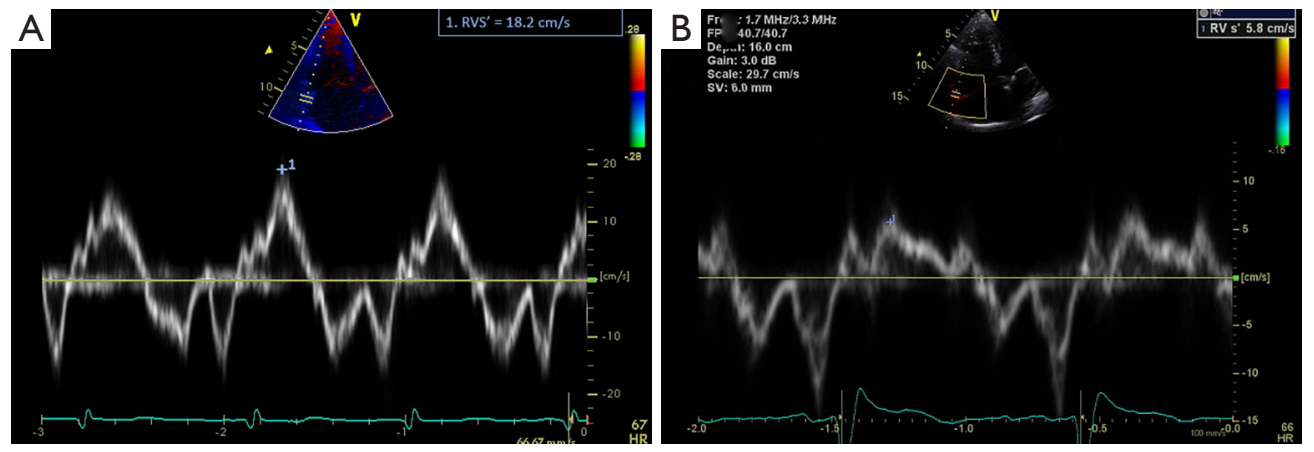

Figure 10 Quantification of right ventricular (RV) systolic function using RVS' in a normal subject where RVS' =18.2 cm/s (A) and in a patient with impaired RV function due to pulmonary hypertension with reduced RVS' of $5.8 \mathrm{~cm} / \mathrm{s}$ (B).
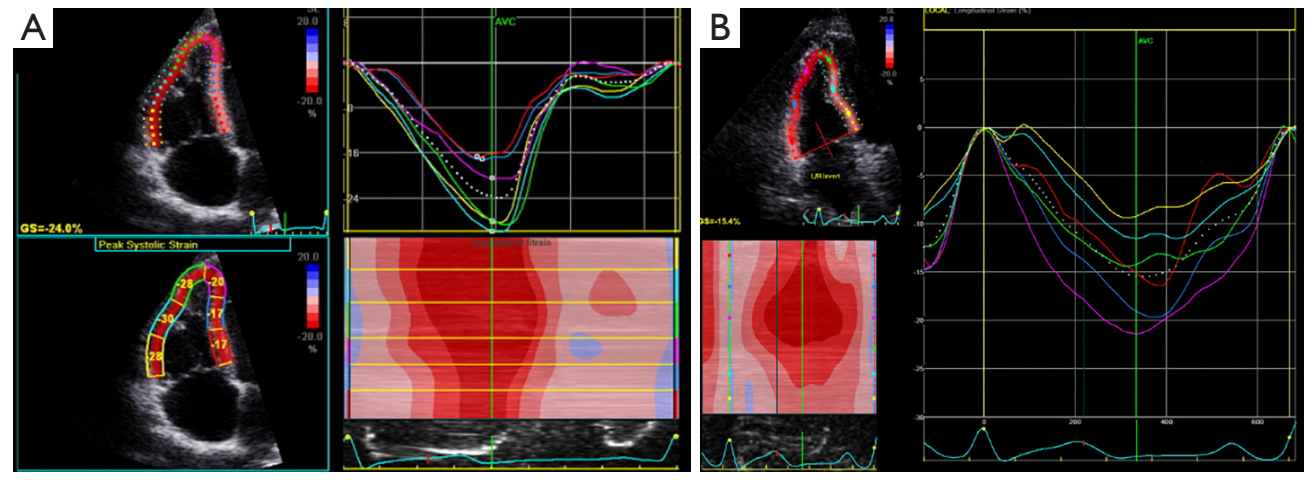

Figure 11 Measurement of right ventricular (RV) global longitudinal strain using speckle-tracking. Panel (A) shows a normal subject. The patient in (B) has pulmonary hypertension with reduced RV global strain of $15.4 \%$.

and observer error (31). At our institution, we routinely measure TAPSE and RV S'.

\section{RV diastolic function assessment using echo}

Increased RAP, increased RV wall thickness and abnormal $\mathrm{RV}$ relaxation all contribute to diastolic dysfunction in patients with PH. RV diastolic dysfunction can be assessed using various echo parameters including RA size, E/e' ratio, $\mathrm{E} / \mathrm{A}$ ratio and the deceleration time. It must be noted however that these parameters are not validated in the setting of severe tricuspid regurgitation and their potential role in the assessment of $\mathrm{PH}$ is currently unclear.

Echocardiography remains challenging, inherently due to the geometry and position of the RH within the thoracic cavity (31). Discrepancy between non-invasive and invasive hemodynamic measurements may occur due to poor image quality and operator related measurement error. The latter is primarily due to misalignment of the continuous wave cursor with the tricuspid regurgitant jet or inaccurate tracing of the TR signal envelope. The ESC guidelines for identification of $\mathrm{PH}$ take a slightly different approach and classify the likelihood of $\mathrm{PH}$ as low, intermediate or high, based on the peak TR velocity and whether there are other features suggestive of $\mathrm{PH}$ are present. Peak TR velocity cutoffs of 2.8 and $3.4 \mathrm{~m} / \mathrm{s}$ are used to define risk (3). Attempts have been made to measure PVR non-invasively $(52,53)$, but have not demonstrated satisfactory accuracy to warrant routine clinical adoption.

\section{Transesophageal echocardiography}

In some cases, transesophageal echocardiography (TEE) may be required to further evaluate findings from TTE or other imaging modalities. Detailed evaluation of mitral valve disease to determine severity and elucidate an underlying mechanism may help decide whether surgery is required. Assessment of intracardiac shunts, particularly those at the atrial level, and pulmonary vein anatomy may provide additional diagnostic information regarding the 
cause of $\mathrm{PH}$ and guide treatment.

\section{Computed tomography}

High resolution computed tomography (HRCT) scanning is the primary imaging modality for the assessment of lung parenchyma, while CT pulmonary angiography (CTPA) allows for the non-invasive assessment of the pulmonary arteries (3). The advantages of CT include excellent spatial resolution, expanded field of view and the ability to perform multi planar reconstruction.

Dilatation of the main pulmonary artery (MPA) is a

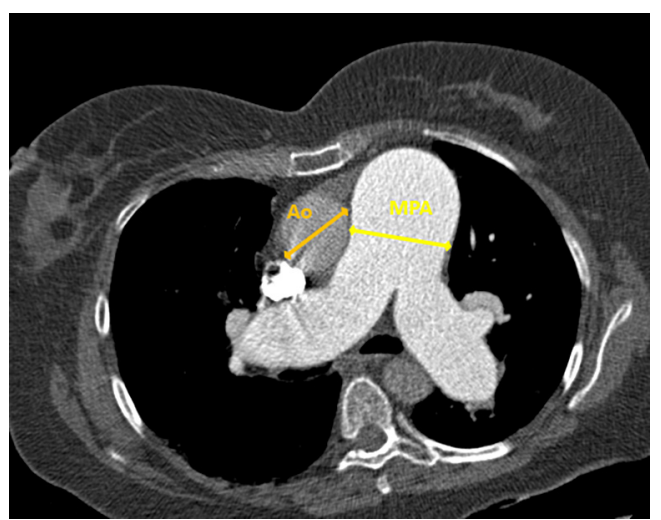

Figure 12 CT scan of the chest in a 71-year-old male with marked pulmonary hypertension on the background of COPD and previous pulmonary emboli. The dilated main pulmonary artery (MPA) is larger than the adjacent ascending aorta (Ao).

sensitive and specific finding in PH. An MPA of $>2.9 \mathrm{~cm}$ has specificity of $89 \%$ for $\mathrm{PH}(15,54,55)$. A ratio of diameter of MPA to the ascending aorta $>1.0$ is an additional sensitive predictor of $\mathrm{PH}$ (Figure 12) (54). A dilated right or left pulmonary artery $>1.8 \mathrm{~cm}$ is also indicative of $\mathrm{PH}$ and a predictor of mortality. In chronic $\mathrm{PH}$, mural calcification, increased vascular remodelling, tortuosity and pruning of the peripheral branches are classically described features (54). However, these CT findings are somewhat limited by a low negative predictive value. Furthermore, patients with parenchymal lung pathology without $\mathrm{PH}$ can also have some of the above features.

HRCT scanning is the primary investigation of choice to detect Class $3 \mathrm{PH}$ patients i.e., patients with lung parenchymal abnormality. Pathological conditions such as chronic obstructive airways disease, interstitial lung disease, Langerhans cell histiocytosis, sarcoidosis or pneumonitis increase the load on the RH (Figure 13). Some of the HRCT parenchymal features of patients with $\mathrm{PH}$ are described in Table 4.

Cardiac findings on CT reflect adverse remodelling of the RH due to chronic pressure overload. Common features include RV hypertrophy (wall thickness $>5 \mathrm{~mm}$ ) and a dilated $\mathrm{RV}$ with a $\mathrm{RV} / \mathrm{LV}$ ratio $>1.0$ in the axial plane. Other findings including a flattened interventricular septum, contrast reflux into the IVC and dilatation of the inferior vena cava. Pericardial effusions and dilatation of the RA are non-specific signs that may be associated with $\mathrm{PH}$.

The strength of contrast CT scanning is in the detection
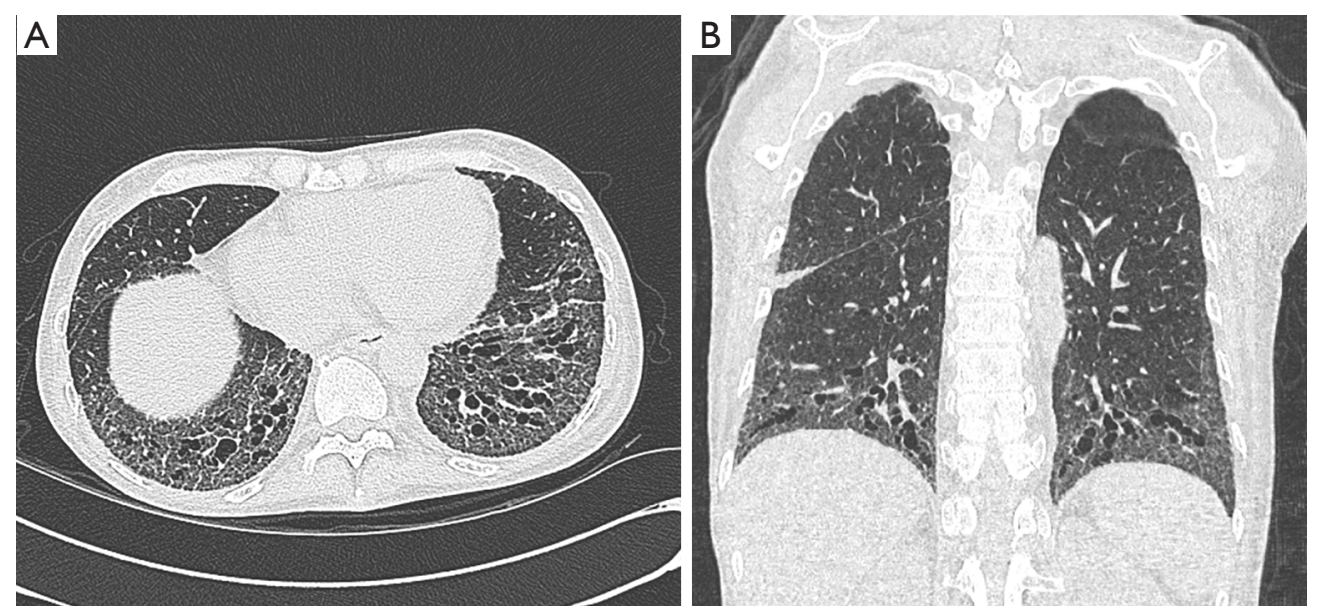

Figure 13 Coronal reconstruction (A) and axial slice (B) from a CT scan of the chest showing changes of interstitial lung disease. Sub-pleural and predominantly basal reticulation and mild traction bronchiectasis with ground glass opacity suggestive of pulmonary fibrosis in a 61-year-old female. 
Table 4 Features of pulmonary hypertension on CT scan

\begin{tabular}{lll}
\hline Pathology & Lung parenchymal changes & Best modality for confirmation \\
\hline CTEPH & Mosaic pattern from perfusion heterogeneity & Ventilation perfusion nuclear scan \\
& Infarction & Pulmonary function test \\
COPD & Hyperinflated lungs with alveolar septal destruction and airspace enlargement & Lung biopsy \\
PVOD & Septal lines, centrilobular ground glass opacities, lymphadenopathy & \\
\hline
\end{tabular}

CTEPH, chronic thromboembolic pulmonary hypertension; COPD, chronic obstructive pulmonary disease; PVOD, pulmonary veno-occlusive disease

of patients with acute pulmonary embolic disease, which if left unrecognised and untreated, may lead to Class 4 $\mathrm{PH}$ or CTEPH. CTPA requires the IV administration of iodinated contrast agent to visualize the pulmonary arteries down to the subsegmental level. It has now become the widely accepted modality of choice to diagnose acute PE $(56,57)$. This has largely supplanted ventilation-perfusion nuclear medicine techniques in the detection of acute pulmonary emboli in patients who do not have contrast allergy or significant renal impairment. CT provides additional information about lung parenchyma and cardiac morphology in addition to the assessment of the pulmonary vasculature (58). Unlike acute PE, the role of CTPA is not as well established in excluding CTEPH, given the fact that emboli can still be present in high volumes in the very distal and small vasculature, and can be missed on this modality.

An additional benefit of CTPA is the diagnosis of pulmonary arteriovenous malformations seen in conditions such hereditary haemorrhagic telangiectasia, a Group 1 cause of $\mathrm{PH}$. These ateriovenous malformations appear as a nodular opacity with a feeding artery and a draining vein.

Dual Energy CT involves acquiring imaging at two different $\mathrm{x}$-ray photon spectra. This can be performed via a number of different techniques and requires an "enabled" scanner and the appropriate reconstruction software, generally with IV contrast. Iodine/contrast or pulmonary blood volume maps of the lung can be obtained and reflect parenchymal perfusion (59). When combined with traditional CTPA and CT Chest, this can provide a form of Ventilation-Perfusion imaging. These techniques have been used to increase sensitivity of CTPA. The utility of this form of CT has yet to be convincingly demonstrated to be equivalent or superior to traditional nuclear medicine imaging, though from a physiological perspective one could infer that the results could be similar. Head to head studies will be required, though with the lack of convenient gold standard, and rareness of CTEPH, it may take some time (if at all) for such a study to be performed.

\section{Radionuclide ventilation perfusion scanning (V/Q Scanning)}

V/Q scanning is used in the diagnosis of CTEPH or class $4 \mathrm{PH}$ when all other investigations have not yielded a clear aetiology. It has $>90 \%$ sensitivity and specificity for this role (60). Chronic pulmonary embolic disease is usually diagnosed when there are a number of segmental mismatched perfusion defects with preserved ventilation to the corresponding regions (Figure 14), in the absence of any other explanation. There are several limitations of the modality, including non-diagnostic studies or cases of matched defects which may occur in PAH. Single photon emission computer tomography (SPECT) has largely replaced the planar techniques, given the advantages of viewing ventilation and perfusion defects in any plane post reconstruction. Often low dose co-registered CT (i.e., SPECT/CT) is performed following an abnormal study, to help exclude lung parenchymal abnormalities e.g., tumour/ effusion/consolidation/fibrosis.

Traditionally, V/Q imaging is performed with gas (Xe133) or aerosolised droplets (Technetium 99M, DTPA/MDP/ Sulfur colloid) or Carbon particles "Technegas" (61), for the ventilation phase and Technetium labelled macroaggregated albumin (MAA) for the perfusion. Techniques involving positron emission tomography (PET) involving Ga68, as both a ventilation ("Galligas" via aerosolised carbon particles) and a perfusion agent (Ga-68 MAA), have been described and used clinically at some sites around the world as an alternative to traditional V/Q. The higher sensitivity, spatial and temporal resolution are expected via PET/CT imaging. However, the significant increases in costs and complexity and regional regulatory issues, may restrict this technique to isolated specialist centers $(62,63)$. There has yet to be any notable publications in regard to the use in the 


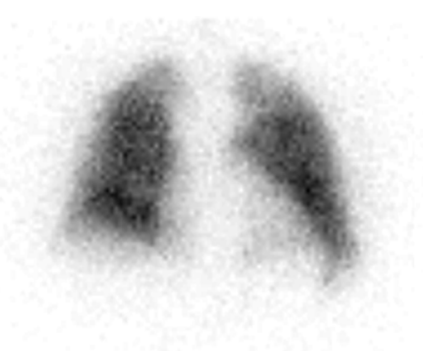

ANT V

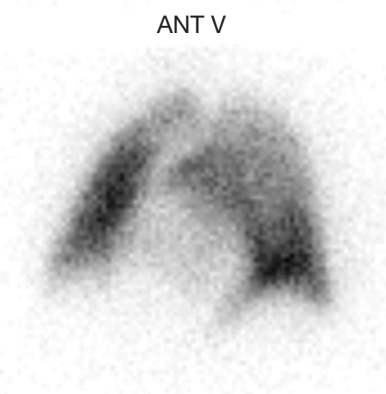

LAO V

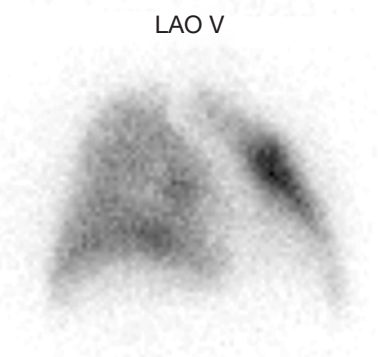

RAO V

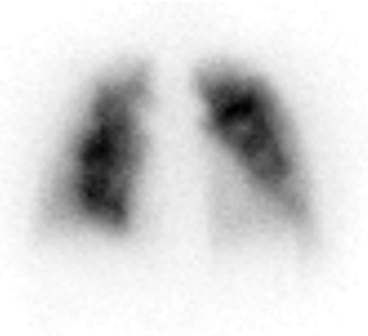

ANT Q

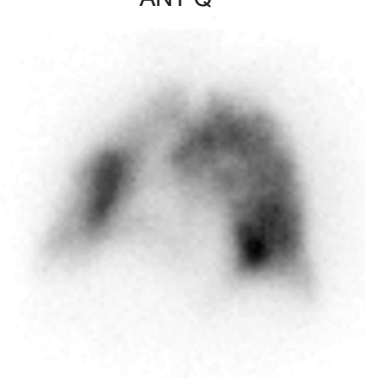

LAO Q

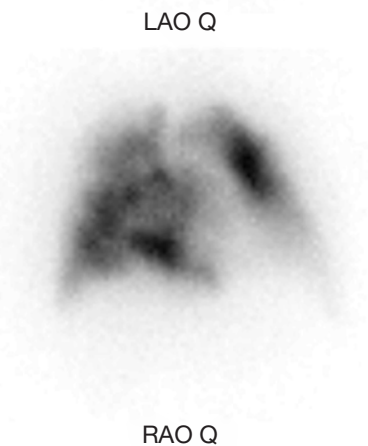

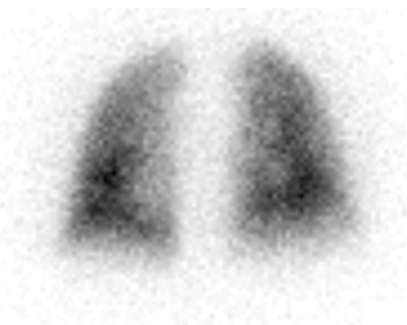

POST V

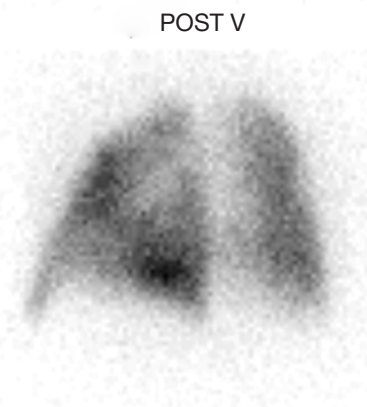

LPO V

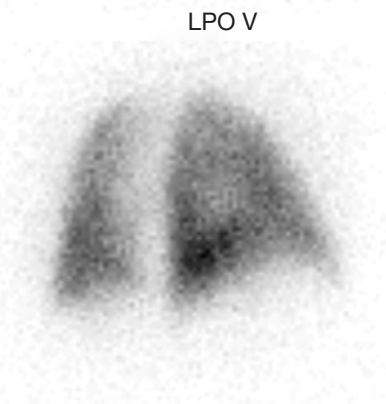

RPO V

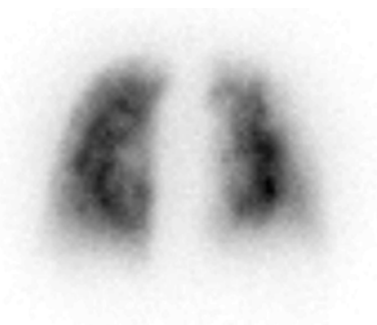

POST Q

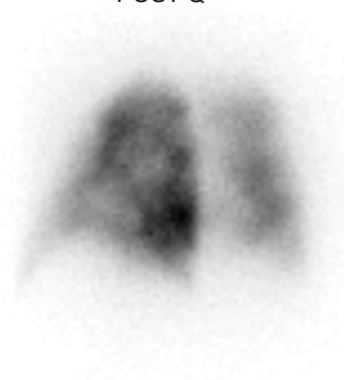

LPO Q

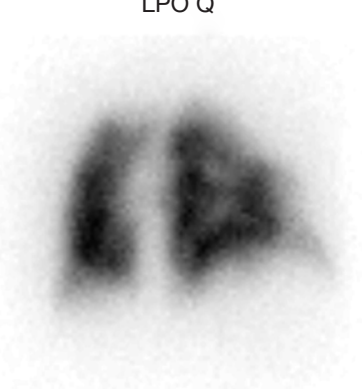

RPO Q

Figure 14 Ventilation-perfusion lung scan with multiple unmatched perfusion defects consistent with chronic thromboembolic pulmonary hypertension (CTEPH) in a 71-year-old male.

evaluation of CTEPH.

If operative or interventional treatment is being considered, a positive V/Q scan requires confirmation using pulmonary angiography. In highly experienced centres, CTPA may be used $(64,65)$.

\section{Cardiac magnetic resonance imaging (CMRI)}

CMRI provides excellent morphological and functional characterisation of the RH. It is the gold standard in the evaluation of RV size and function overcoming the complex geometry and trabeculation due to the excellent spatial and contrast resolution (Figure 15) (66). In addition, CMR provides high-resolution time-resolved 3-dimensional (3D) volumetric visualization of the RH, quantification of blood flow enabling calculation of regurgitant valvular flow, identification of congenital cardiac abnormalities including shunts and assessment of tissue characteristics such as myocardial fibrosis and scarring (66-70). While there is no ionising radiation exposure, the main limitations are the time required to perform and restrictions arising from implanted metallic objects or devices within the patient. CMR sequences and their utility in PH is listed in Table 5.

All morphological measurements used in TTE and CT are directly applicable to CMR in patients with PH. Dilated central pulmonary arteries, which are evaluated in anatomy sequences or MR angiography phase contrast sequences demonstrating an MPA diameter of $>2.9 \mathrm{~cm}$ or ratio of MPA to ascending aortic diameter $>1$ all correlate directly with $\mathrm{PH}$. On velocity-encoded phase contrast images, low velocity in the main pulmonary artery (i.e., 

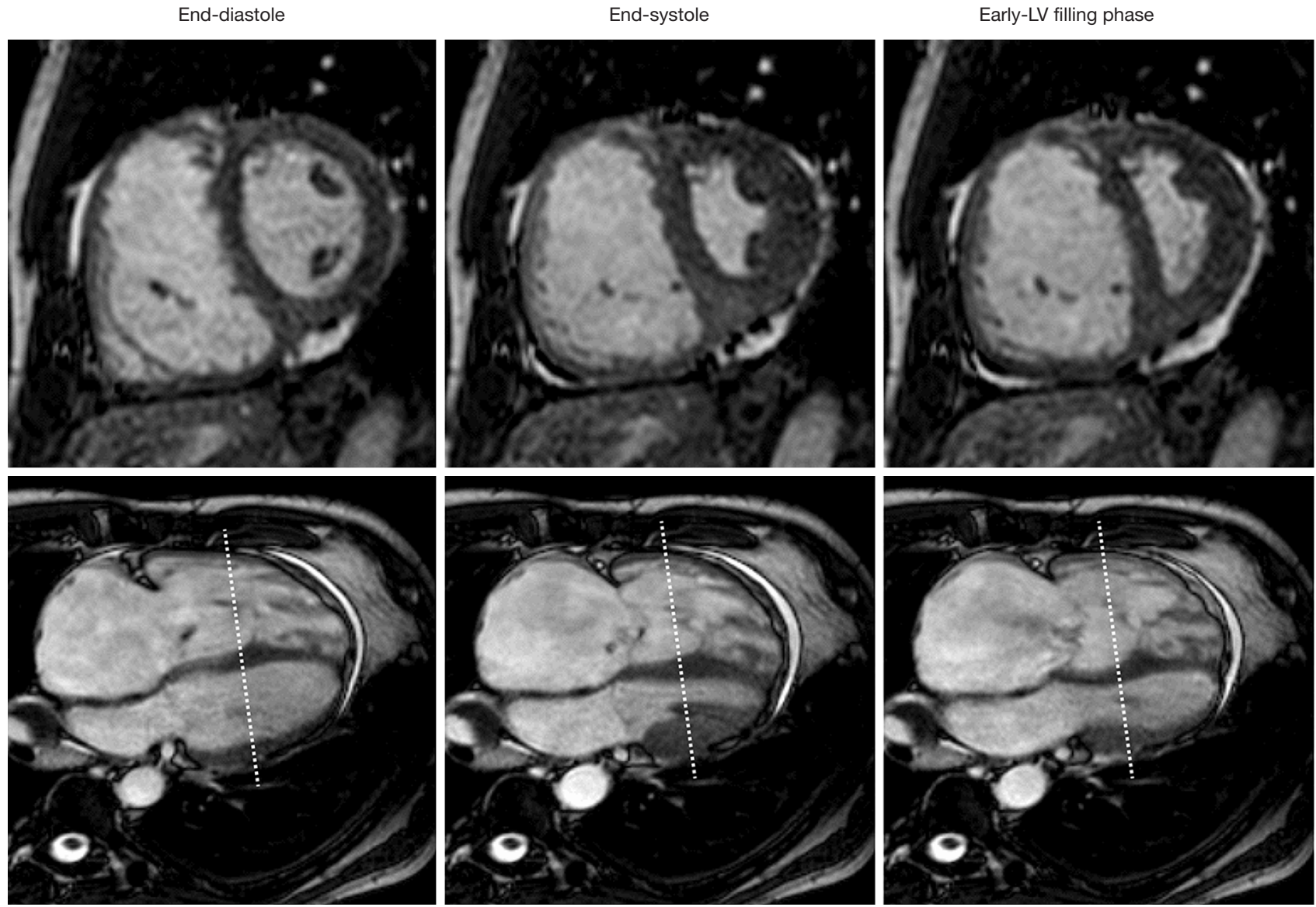

Figure 15 Cardiac SSFP images on a patient with chronic thromboembolic pulmonary hypertension (CTEPH). The upper panels shows short axis views at end-diastole, end-systole and in the early-left ventricular (LV) diastolic filling phase. The lower panels show 4-chamber views with the position of the short axis planes shown. The right ventricle (RV) and right atrium are dilated. The short axis views demonstrate with a dilated right ventricle and marked flattening of the interventicular septum at end-systole producing a D-shaped left ventricle due to RV pressure overload. In the early-LV filling phase there is additional septal shift with increased pressure gradient between the RV and the LV causing reversal of the normal septal curvature. A small pericardial effusion is also noted. Images courtesy of Dr Guido Classsen.

Table 5 Common cardiac MRI sequences in pulmonary hypertension

\begin{tabular}{ll}
\hline Cardiac MRI Sequence & Role in pulmonary hypertension \\
\hline Black blood double inversion recovery & LV and RV morphology \\
SSFP Cine imaging & LV and RV function and volumetric assessment \\
Phase contrast velocity encoded imaging & Intracardiac flow, regurgitant volume, shunt ratio, non-invasive hemodynamics \\
Modified look locker imaging & T1 based marker of fibrosis and fatty infiltration \\
Late gadolinium enhancement & Tissue Characterisation and Fibrosis correlated with Prognosis \\
T1, T2 mapping & Fibrosis, edema, prognosis \\
MR angiography & Vascular abnormalities, perfusion \\
\hline
\end{tabular}


$<11.7 \mathrm{~cm} / \mathrm{s}$ ) and early retrograde flow are both suggestive of PH $(71,72)$.

RV cardiac output can be estimated by multiplying the determined RV stroke volume (SV) by the heart rate during the image acquisition of the cine stacks. In one study, individuals with $\mathrm{mPAP} \geq 30 \mathrm{mmHg}$ and a systolic leftward deviation of the IVS had $86 \%$ sensitivity and $91 \%$ specificity for detecting PH. Finally, RV mass is greater in $\mathrm{PH}$ when compared to healthy controls; a ventricular mass index (RV mass divided by $\mathrm{LV}$ mass) $>0.6$ is suggestive of $\mathrm{PH}(71)$.

Delayed enhancement CMR imaging post administration of a gadolinium-based contrast agent (GBCA) is utilised to identify areas of prolonged retention (i.e., delayed clearance) of GBCA from the extracellular space, a specific marker of fibrosis. In $>30 \%$ of patients with $\mathrm{PH}$, enhancement is seen at the RV septal insertion sites near the base of the heart (71). It is thought that these sites represent areas of increased mechanical stress and the presence of delayed enhancement in these areas correlates to reduced RVEF, RV dilation and increased mPAP (73).

\section{CMR and left heart assessment}

Left heart disease, including both HFrEF and heart failure with preserved ejection fraction (HFpEF), is the most common cause of $\mathrm{PH}(45,74)$. Chronic impairment left ventricular contractile function due to a primary myopathic process or left sided valvular dysfunction results in elevated post capillary pulmonary pressures (75). Irrespective of the underlying etiology, PH due to left sided HFREF is associated with poor long-term outcomes $(46,76,77)$. The focus of management in patients with $\mathrm{PH}$ due to HFREF is treatment of the underlying cause of left ventricular dysfunction with guideline-directed heart failure therapy and percutaneous or surgical correction of valvular dysfunction where required (78).

If features of patient history suggest $\mathrm{LH}$ or congenital disease as a cause (Group $2 \mathrm{PH}$ ), particular sequences can be integrated into the MRI protocol which allow for visualisation of the pulmonary veins, assessment of shunts and the quantification of valvular disease.

Furthermore, CMR may provide important diagnostic information about the etiology of the cardiomyopathic processes. The extent of $\mathrm{LV}$ dysfunction and the presence of fibrosis on MRI are key CMR parameters which have prognostic implications. The specific pattern of LGE aids in differentiating between ischaemic and non-ischaemic cardiomyopathies.

\section{CMR and prognosis}

$\mathrm{RV}$ function is the main determinant of outcome in patients with PH $(16,19,20)$. CMR is considered the gold standard for assessment of RV structure and function and can therefore be used to predict outcome and assess response to therapy in patients with $\mathrm{PH}$. CMR parameters including $\mathrm{RV}$ volume, $\mathrm{RV}$ mass and $\mathrm{RV}$ function have all been shown to be predictors of poor outcomes in $\mathrm{PH}$ patients $(16,79)$. In patients with iPAH, a dilated RV (RVEDVi $>84 \mathrm{~mL} / \mathrm{m}^{2}$ ) and reduced RV SV $\left(<25 \mathrm{~mL} / \mathrm{m}^{2}\right)$ predicts treatment failure and mortality $(71,79)$. RVEF $<35 \%$, independent of PVR, has been shown to be a predictor of survival in patients with Group $1 \mathrm{PAH}$ on targeted PAH therapy (80). In patients with systemic sclerosis associated $\mathrm{PH}$, ventricular mass index (end diastolic mass of RV:LV) $>0.7$ has been shown to be a predictor of 2-year survival and correlates with mPAP in these patients (79). LGE at the RV insertion points (RVIP-LGE) reflects chronically elevated RV pressure and increased wall stress. A study by Freed $e t$ al. showed that RVIP-LGE was a marker for more severe RV dysfunction (increased RVEDVi, lower RVEF, increased mPAP) and predicted clinical deterioration and reduced exercise capacity in patients with $\mathrm{PH}(81)$.

CMR parameters involving PA distensibility, such as pulmonary artery relative area change $(<16 \%)$ and pulsatility of deformation, are associated with increased mortality in patients with PAH $(82,83)$. These measures reflect increased PA stiffness which results in increased RV afterload and correlates to worsening hemodynamic parameters. Pulmonary artery stiffness and slow flow in the main PA correlates with elevated mPAP and PVR and has been linked to worse outcomes (84).

\section{Novel imaging techniques in PH}

\section{Echocardiography}

There is great interest in identifying new non-invasive parameters that may help improve diagnosis, classification and prediction of prognosis in $\mathrm{PH}$. Scalia et al. described a novel parameter called the echocardiographic pulmonary to left atrial ratio (ePLAR) which can be used to non-invasively distinguish between pre-capillary and post-capillary $\mathrm{PH}$ (85). The ePLAR combines a marker of elevated pulmonary pressure with a marker of elevated PAWP to enable the differentiation of pre and post capillary PH. The ePLAR is estimated utilising the maximal velocity of the tricuspid incompetence jet, which is a surrogate for right sided 
pressures or mPAP divided by the tissue Doppler derived E/e' velocity of the mitral annulus, which is a surrogate for PAWP. In their study, the normal reference population had ePLAR values of $0.30 \pm 0.09 \mathrm{~m} / \mathrm{s}$. Patients with pre-capillary $\mathrm{PH}$ had significantly higher ePLAR values than their normal counterparts (ePLAR $0.44 \pm 0.22 \mathrm{~m} / \mathrm{s}$ ). Post capillary PH patients who had elevated PAWP had a significantly lower value than their normal counterparts (ePLAR $0.20 \pm 0.11 \mathrm{~m} / \mathrm{s}, \mathrm{P}<0.001)$. In more complex cases with both right and left sided disease, patients with combined pre- and post-capillary $\mathrm{PH}$ demonstrated intermediate values (ePLAR $0.28 \pm 0.18 \mathrm{~m} / \mathrm{s}$ ). This group of patients still demonstrated a significantly higher ePLAR than patients with isolated post-capillary $\mathrm{PH}(85)$.

Strain imaging is an additional novel parameter that utilises tissue Doppler or speckle tracking modes to provide further quantitative measures of RA, LA, LV and RV function. By measuring strain (RV global longitudinal strain and RV free wall strain) and strain rate, pathological states such as $\mathrm{PH}$ and the degree of myocardial dysfunction can be reproducibly tracked (86-88). RV free wall strain is preferred over RV GLS as it excludes tracking of the interventricular septum which may be affected by left heart disease. This parametric measure of function can be used to follow response to therapy and predicts prognosis in patients with $\mathrm{PH}(89)$.

Real-time $3 \mathrm{D}$ echo is also an exciting modality within TTE that allows more accurate measurements of RV volume and systolic function when compared to $2 \mathrm{D}$ echo (88). Combining both strain imaging and $3 \mathrm{D}$ imaging in the echocardiographic assessment of the RH is the next frontier with regard to the comprehensive management of patients with $\mathrm{PH}$.

\section{Hybrid CT and nuclear perfusion imaging}

CT and nuclear medicine systems can be combined, drawing on the strengths of both modalities in the assessment of the $\mathrm{RH}$ in patients with $\mathrm{PH}$. Multiple variables across the different imaging modalities can be characterized simultaneously in a single study, making this a truly exciting next frontier for both imaging modalities.

Single photon emitting CT or SPECT and CT are merged in various pathological states to gain anatomic data. This is then combined with perfusion analysis to be able to identify parenchymal abnormality and perfusion defects (90,91).

Positron emitting tomography (PET) in combination with CT is now widely utilised in the diagnosis of multiple pathological states such as cardiac sarcoidosis and cardiac amyloidosis (92). Its high spatial resolution allows improved RV visualization and with the addition of the FDG PET scanning, can quantify metabolic substrates as a surrogate to allow for additional tissue characterisation (93-95). In patients with $\mathrm{PH}$, accumulation of FDG, which is a measure of tissue metabolism, is elevated in the RV free wall. Higher degrees of FDG uptake in the RV has been showed to be associated with worse clinical outcomes (95).

\section{MR pulmonary angiography and perfusion}

MR has potential as a technique without nephrotoxic agents and ionisation radiation. However, the results of PIOPED III study, where the proportion of technical inadequate images ranged from $11 \%$ to $52 \%$ at various centres, illustrates the difficulty in such techniques (96). Progression in technique and protocols are expected. MR angiographic techniques are a valid alternative in some regions of the body. More recent results in single centres are promising, although future multicentre studies are required to assess the real clinical value of MRI (97).

Intravascular (blood pool agents) show promise but the gadolinium agent gadofosveset trisodium is no longer manufactured. The superparamagnetic iron oxide agent ferumoxytol is approved for human use by the FDA for treatment iron deficiency anaemia in those intolerant of oral replacement. Numerous publications have demonstrated the off-label use of this substance as a MR contrast agent, specifically for vascular imaging and pulmonary angiography in the setting of acute pulmonary embolic disease (98-100). These techniques could potentially extend into the evaluation of CTEPH.

\section{Cardiac MRI}

T1 parametric mapping enables excellent tissue characterisation and directly correlates with LGE defined fibrotic burden $(101,102)$. This well validated sequence in patients with $\mathrm{PH}$ allows for the identification of diffuse fibrosis and scar formation in the RV, which has been correlated to long term outcomes and prognosis (101). It has been shown that RV T1 mapping values correlate with pulmonary hemodynamics and RV-PA coupling, which are all reproducible indicators of RV dysfunction (101). In addition, the generation of an extracellular volume (ECV) map using gadolinium based contrast, enables quantification 
of the ECV, another marker of cardiac fibrosis $(102,103)$. Increased T1 mapping values at the RV/LV insertion points has promise in the detection of early RV failure and may have a role in determining treatment response in $\mathrm{PH}$ (101-103).

Myocardial tagging and strain analysis utilising a fast strain encoded (SENC) sequence enables the measurement of regional ventricular deformation before any overt deterioration in global RV function may occur $(36,104)$. In patients with $\mathrm{PH}, \mathrm{RV}$ strain and strain rate have been demonstrated to be predictors of $\mathrm{RH}$ failure and mortality (104).

4D Flow MRI has provided unprecedented insights into hemodynamics of various diseases and vascular territories (105). In $\mathrm{PH}$, Reiter and co-workers established means of non-invasively diagnosing $\mathrm{PH}$ by estimating the mPAP using presence and persistence time of secondary flow patterns in the main pulmonary artery. This is a promising sequence that requires larger scale studies and invasive correlation (105-107).

CMR that involves the quantitative analysis of helicity and vorticity of $\mathrm{PA}$ flow in $\mathrm{PH}$ patients can be used to indirectly assess RV function $(106,108)$. These parameters could potentially be used to better predict outcome and survival in those newly diagnosed with $\mathrm{PH}$, independent of traditional risk factors. The potential benefit, similar to strain imaging, is the early diagnosis of $\mathrm{RV}$ dysfunction before traditional methods can detect myocardial dysfunction, enabling more aggressive treatment of the underlying pathology $(83,109)$.

\section{Stress testing in PH}

Exercise testing of the pulmonary circulation is thought to be an effective diagnostic undertaking in unmasking increased PVR and/or reduced pulmonary vascular compliance in patients that may be asymptomatic at rest. Exercise limitation is seen in patients with $\mathrm{PH}$ due to a variety of factors, including reduced RV stroke volume (RV SV) as a consequence of RV dysfunction, pulmonary vasoconstriction, or by increased upstream transmission of pulmonary venous pressure (110-112). A reduction in RV contractile reserve, which can be quantified using invasive pressure volume loop derived indices, is also postulated to be a contributor to exercise-induced PH (113). Noninvasive methods to evaluate right sided hemodynamic parameters at peak exercise are predominantly echocardiogram based (both exercise and dobutamine stress echocardiography). Recent advancements in CMR techniques have enabled reproducible methods of assessing
RV function and pulmonary artery compliance during peak exercise (114).

\section{Dobutamine stress echo}

Dobutamine stress echocardiography allows the assessment of pulmonary artery pressure-cardiac output (mPpA-Q) response (115). Systolic pulmonary artery pressures are derived from the peak tricuspid regurgitation jet, and mPAP is then derived using the formula 0.6 X Systolic PA + 2 (115). $\mathrm{RV} \mathrm{SV}$ is derived from the RVOT velocity time integral $x$ RVOT Area, with subsequent cardiac output derived by multiplying the SV by the patient's heart rate. This enables the relationship of the $\mathrm{mPpA}-\mathrm{Q}$ ratio to be derived. The $\mathrm{mPpA}-\mathrm{Q}$ has been demonstrated to be a reproducible indicator of elevated exercise pulmonary pressures that is accounted for by the physiologic increase in cardiac output during exercise $(115,116)$. Patients with exercise induced $\mathrm{PH}$ have been shown to have a higher dobutamine-induced $\mathrm{mPpA}-\mathrm{Q}$ slope when compared to healthy controls (116). Pulmonary artery compliance, as expressed by the derived distensibility coefficient $\mu$, is another parameter that can be measured during stress echocardiography. Pulmonary artery compliance has been found to be markedly reduced in the PH group (115).

The benefit of dobutamine stress echocardiography over conventional exercise stress echocardiography is the ability to maintain sustained maximal cardiac capacity for longer periods of time. This enables more accurate measurements of right sided echocardiographic parameters, as opposed to a finite window afforded by treadmill or cycle ergometer.

\section{Stress Cardiac MRI}

Stress CMR may offer additional insights in PH. Exercise CMR techniques exist which have provided promising results in CTPEH (114). Examination of pulmonary artery flow parameters with vasodilator stress provides unique prognostic information in $\mathrm{PAH}$ (117) and appears promising for early detection of pulmonary vascular disease (118). Stress CMR enables the vastly superior spatial resolution afforded by MRI imaging to be coupled with non-invasive assessment of the heart during peak exercise $(119,120)$. La Gerche et al. validated an exercise CMR technique that enabled the accurate and reproducible quantification of biventricular volumes, flow and function during strenuous exercise (119). With this technique, they were able to demonstrate that exercise intolerance in patients with 
CTEPH, which persisted post pulmonary endarterectomy despite normal resting mPAP, is reflected by abnormal pulmonary vascular reserve, failure to augment RVEF and chronotropic incompetence during exercise (114). Exercise-induced RV-pulmonary artery uncoupling, which is an additional parameter that was demonstrated to correlate well with exercised induced $\mathrm{PH}$, can also be derived utilising stress CMR sequences (120). These additional parameters represent exciting further options in the evaluation of exercise induced PH with CMR.

\section{Conclusions}

Multimodality imaging plays a vital role in the current identification, management and prognostication of patients with PH. Imaging guides the accurate classification of $\mathrm{PH}$ into its defined etiological groups and directly guides treatment suitability and management. TTE, CT and MRI have echo proven to provide robust and accurate prognostic information specific to patients with $\mathrm{PH}$. With the validation of novel and hybrid imaging techniques there is likely to be less reliance on invasive testing or surrogate markers such as the 6-minute walk test for both research and clinical management.

\section{Acknowledgments}

Thank you to Dr Guido Claessen for providing the images in Figure 15.

Funding: None.

\section{Footnote}

Provenance and Peer Review: This article was commissioned by the Guest Editors (Deborah H. Kwon and Bo Xu) for the series "Heart Valve Disease" published in Cardiovascular Diagnosis and Therapy. The article has undergone external peer review.

Conflicts of Interest: All authors have completed the ICMJE uniform disclosure form (available at http://dx.doi. org/10.21037/cdt-20-295). The series "Heart Valve Disease" was commissioned by the editorial office without any funding or sponsorship. DLP reports personal fees from Janssen-Cilag Pty Ltd., and Novartis Pharamaceuticals Australia, outside the submitted work. The authors have no other conflicts of interest to declare.
Ethical Statement: The authors are accountable for all aspects of the work in ensuring that questions related to the accuracy or integrity of any part of the work are appropriately investigated and resolved.

Open Access Statement: This is an Open Access article distributed in accordance with the Creative Commons Attribution-NonCommercial-NoDerivs 4.0 International License (CC BY-NC-ND 4.0), which permits the noncommercial replication and distribution of the article with the strict proviso that no changes or edits are made and the original work is properly cited (including links to both the formal publication through the relevant DOI and the license). See: https://creativecommons.org/licenses/by-nc-nd/4.0/.

\section{References}

1. Simonneau G, Montani D, Celermajer DS, et al. Haemodynamic definitions and updated clinical classification of pulmonary hypertension. Eur Respir J 2019;53:1801913.

2. Kovacs G, Berghold A, Scheidl S, et al. Pulmonary arterial pressure during rest and exercise in healthy subjects: a systematic review. Eur Respir J 2009;34:888-94.

3. Galiè N, Humbert M, Vachiery JL, et al. 2015 ESC/ERS Guidelines for the diagnosis and treatment of pulmonary hypertension: The Joint Task Force for the Diagnosis and Treatment of Pulmonary Hypertension of the European Society of Cardiology (ESC) and the European Respiratory Society (ERS): Endorsed by: Association for European Paediatric and Congenital Cardiology (AEPC), International Society for Heart and Lung Transplantation (ISHLT). Eur Heart J 2016;37:67-119.

4. Galiè N, McLaughlin VV, Rubin LJ, et al. An overview of the 6th World Symposium on Pulmonary Hypertension. Eur Respir J 2019;53:1802148.

5. Weitzenblum E, Hirth C, Ducolone A, et al. Prognostic value of pulmonary artery pressure in chronic obstructive pulmonary disease. Thorax 1981;36:752-8.

6. Bishop JM, Cross KW. Physiological variables and mortality in patients with various categories of chronic respiratory disease. Bull Eur Physiopathol Respir 1984;20:495-500.

7. Hamada K, Nagai S, Tanaka S, et al. Significance of pulmonary arterial pressure and diffusion capacity of the lung as prognosticator in patients with idiopathic pulmonary fibrosis. Chest 2007;131:650-6. 
8. Kovacs G, Maier R, Aberer E, et al. Borderline pulmonary arterial pressure is associated with decreased exercise capacity in scleroderma. Am J Respir Crit Care Med 2009;180:881-6.

9. Bae S, Saggar R, Bolster MB, et al. Baseline characteristics and follow-up in patients with normal haemodynamics versus borderline mean pulmonary arterial pressure in systemic sclerosis: results from the PHAROS registry. Ann Rheum Dis 2012;71:1335-42.

10. Valerio CJ, Schreiber BE, Handler CE, et al. Borderline mean pulmonary artery pressure in patients with systemic sclerosis: transpulmonary gradient predicts risk of developing pulmonary hypertension. Arthritis Rheum 2013;65:1074-84.

11. Maron BA, Brittain EL, Choudhary G, et al. Redefining pulmonary hypertension. Lancet Respir Med 2018;6:168-70.

12. Simonneau G, Gatzoulis MA, Adatia I, et al. Updated clinical classification of pulmonary hypertension. J Am Coll Cardiol 2013;62:D34-41.

13. Benza RL, Miller DP, Gomberg-Maitland M, et al. Predicting survival in pulmonary arterial hypertension: insights from the Registry to Evaluate Early and LongTerm Pulmonary Arterial Hypertension Disease Management (REVEAL). Circulation 2010;122:164-72.

14. Humbert M, Gerry Coghlan J, Khanna D. Early detection and management of pulmonary arterial hypertension. Eur Respir Rev 2012;21:306-12.

15. Tonelli AR, Arelli V, Minai OA, et al. Causes and circumstances of death in pulmonary arterial hypertension. Am J Respir Crit Care Med 2013;188:365-9.

16. D'Alonzo GE, Barst RJ, Ayres SM, et al. Survival in patients with primary pulmonary hypertension. Results from a national prospective registry. Ann Intern Med 1991;115:343-9.

17. Voelkel NF, Quaife RA, Leinwand LA, et al. Right ventricular function and failure: report of a National Heart, Lung, and Blood Institute working group on cellular and molecular mechanisms of right heart failure. Circulation 2006;114:1883-91.

18. Matthews JC, McLaughlin V. Acute right ventricular failure in the setting of acute pulmonary embolism or chronic pulmonary hypertension: a detailed review of the pathophysiology, diagnosis, and management. Curr Cardiol Rev 2008;4:49-59.

19. Badesch DB, Champion HC, Sanchez MA, et al. Diagnosis and assessment of pulmonary arterial hypertension. J Am Coll Cardiol 2009;54:S55-66.
20. Thenappan T, Shah SJ, Rich S, et al. Survival in pulmonary arterial hypertension: a reappraisal of the NIH risk stratification equation. Eur Respir J 2010;35:1079-87.

21. Marwick TH, Chandrashekhar Y. The Right Ventricle: Unforgettable With Imaging. JACC Cardiovasc Imaging 2017;10:1289-90.

22. Rich S, Dantzker DR, Ayres SM, et al. Primary pulmonary hypertension. A national prospective study. Ann Intern Med 1987;107:216-23.

23. Kerr IH. Vascular changes in the lungs on the plain radiograph of the chest. Postgrad Med J 1970;46:3-10.

24. Brown K, Gutierrez AJ, Mohammed TL, et al. ACR Appropriateness Criteria(R) pulmonary hypertension. J Thorac Imaging 2013;28:W57-60.

25. Schmidt HC, Kauczor HU, Schild HH, et al. Pulmonary hypertension in patients with chronic pulmonary thromboembolism: chest radiograph and CT evaluation before and after surgery. Eur Radiol 1996;6:817-25.

26. Hampton AO, Castelman B. Correlation of postmortem chest teleroentgenograms with autopsy findings with special reference to pulmonary embolism and infarction. Am J Roentgenol Radium Ther 1940;43:305-26.

27. Worsley DF, Alavi A, Aronchick JM, et al. Chest radiographic findings in patients with acute pulmonary embolism: observations from the PIOPED Study. Radiology 1993;189:133-6.

28. Hoeper MM, Bogaard HJ, Condliffe R, et al. Definitions and diagnosis of pulmonary hypertension. J Am Coll Cardiol 2013;62:D42-50.

29. Bustamante-Labarta M, Perrone S, De La Fuente RL, et al. Right atrial size and tricuspid regurgitation severity predict mortality or transplantation in primary pulmonary hypertension. J Am Soc Echocardiogr 2002;15:1160-4.

30. Raymond RJ, Hinderliter AL, Willis PW, et al. Echocardiographic predictors of adverse outcomes in primary pulmonary hypertension. J Am Coll Cardiol 2002;39:1214-9.

31. Lang RM, Badano LP, Mor-Avi V, et al. Recommendations for cardiac chamber quantification by echocardiography in adults: an update from the American Society of Echocardiography and the European Association of Cardiovascular Imaging. J Am Soc Echocardiogr 2015;28:1-39.e14.

32. Goda A, Ryo K, Delgado-Montero A, et al. The Prognostic Utility of a Simplified Biventricular Echocardiographic Index of Cardiac Remodeling in Patients with Pulmonary Hypertension. J Am Soc Echocardiogr 2016;29:554-60.

33. Grapsa J, Pereira Nunes MC, Tan TC, et al. 
Echocardiographic and Hemodynamic Predictors of Survival in Precapillary Pulmonary Hypertension: SevenYear Follow-Up. Circ Cardiovasc Imaging 2015;8:e002107.

34. Prins KW, Rose L, Archer SL, et al. Clinical Determinants and Prognostic Implications of Right Ventricular Dysfunction in Pulmonary Hypertension Caused by Chronic Lung Disease. J Am Heart Assoc 2019;8:e011464.

35. Ghio S, Klersy C, Magrini G, et al. Prognostic relevance of the echocardiographic assessment of right ventricular function in patients with idiopathic pulmonary arterial hypertension. Int J Cardiol 2010;140:272-8.

36. Sachdev A, Villarraga HR, Frantz RP, et al. Right ventricular strain for prediction of survival in patients with pulmonary arterial hypertension. Chest 2011;139:1299-309.

37. Haeck ML, Scherptong RW, Marsan NA, et al. Prognostic value of right ventricular longitudinal peak systolic strain in patients with pulmonary hypertension. Circ Cardiovasc Imaging 2012;5:628-36.

38. Okumura K, Humpl T, Dragulescu A, et al. Longitudinal assessment of right ventricular myocardial strain in relation to transplant-free survival in children with idiopathic pulmonary hypertension. J Am Soc Echocardiogr 2014;27:1344-51.

39. Naeije R, Torbicki A. More on the noninvasive diagnosis of pulmonary hypertension: Doppler echocardiography revisited. Eur Respir J 1995;8:1445-9.

40. Grünig E, Janssen B, Mereles D, et al. Abnormal pulmonary artery pressure response in asymptomatic carriers of primary pulmonary hypertension gene. Circulation 2000;102:1145-50.

41. Mukerjee D, St George D, Knight C, et al. Echocardiography and pulmonary function as screening tests for pulmonary arterial hypertension in systemic sclerosis. Rheumatology (Oxford) 2004;43:461-6.

42. Lanzarini L, Fontana A, Campana C, et al. Two simple echo-Doppler measurements can accurately identify pulmonary hypertension in the large majority of patients with chronic heart failure. J Heart Lung Transplant 2005;24:745-54.

43. Moceri P, Baudouy D, Chiche O, et al. Imaging in pulmonary hypertension: Focus on the role of echocardiography. Arch Cardiovasc Dis 2014;107:261-71.

44. Zoghbi WA, Adams D, Bonow RO, et al.

Recommendations for Noninvasive Evaluation of Native Valvular Regurgitation: A Report from the American Society of Echocardiography Developed in Collaboration with the Society for Cardiovascular Magnetic Resonance. J
Am Soc Echocardiogr 2017;30:303-71.

45. Strange G, Playford D, Stewart S, et al. Pulmonary hypertension: prevalence and mortality in the Armadale echocardiography cohort. Heart 2012;98:1805-11.

46. Abramson SV, Burke JF, Kelly JJ, Jr., et al. Pulmonary hypertension predicts mortality and morbidity in patients with dilated cardiomyopathy. Ann Intern Med 1992;116:888-95.

47. Batal O, Dardari Z, Costabile C, et al. Prognostic Value of Pericardial Effusion on Serial Echocardiograms in Pulmonary Arterial Hypertension. Echocardiography 2015;32:1471-6.

48. Mazurek JA, Vaidya A, Mathai SC, et al. Followup tricuspid annular plane systolic excursion predicts survival in pulmonary arterial hypertension. Pulm Circ 2017;7:361-71.

49. Augustine DX, Coates-Bradshaw LD, Willis J, et al. Echocardiographic assessment of pulmonary hypertension: a guideline protocol from the British Society of Echocardiography. Echo Res Pract 2018;5:G11-G24.

50. Jones N, Burns AT, Prior DL. Echocardiographic Assessment of the Right Ventricle-State of the Art. Heart Lung Circ 2019;28:1339-50.

51. Borges AC, Knebel F, Eddicks S, et al. Right ventricular function assessed by two-dimensional strain and tissue Doppler echocardiography in patients with pulmonary arterial hypertension and effect of vasodilator therapy. Am J Cardiol 2006;98:530-4.

52. Abbas AE, Fortuin FD, Schiller NB, et al. A simple method for noninvasive estimation of pulmonary vascular resistance. J Am Coll Cardiol 2003;41:1021-7.

53. Dahiya A, Vollbon W, Jellis C, et al. Echocardiographic assessment of raised pulmonary vascular resistance: application to diagnosis and follow-up of pulmonary hypertension. Heart 2010;96:2005-9.

54. Tan RT, Kuzo R, Goodman LR, et al. Utility of CT scan evaluation for predicting pulmonary hypertension in patients with parenchymal lung disease. Medical College of Wisconsin Lung Transplant Group. Chest 1998;113:1250-6.

55. Bajc $M$, Neilly JB, Miniati $M$, et al. EANM guidelines for ventilation/perfusion scintigraphy : Part 1 . Pulmonary imaging with ventilation/perfusion single photon emission tomography. Eur J Nucl Med Mol Imaging 2009;36:1356-70.

56. Ceriani E, Combescure C, Le Gal G, et al. Clinical prediction rules for pulmonary embolism: a systematic review and meta-analysis. J Thromb Haemost 
2010;8:957-70.

57. Truong QA, Massaro JM, Rogers IS, et al. Reference values for normal pulmonary artery dimensions by noncontrast cardiac computed tomography: the Framingham Heart Study. Circ Cardiovasc Imaging 2012;5:147-54.

58. Bolen MA, Renapurkar RD, Popovic ZB, et al. Highpitch ECG-synchronized pulmonary CT angiography versus standard CT pulmonary angiography: a prospective randomized study. AJR Am J Roentgenol 2013;201:971-6.

59. Ameli-Renani S, Rahman F, Nair A, et al. Dual-energy CT for imaging of pulmonary hypertension: challenges and opportunities. Radiographics 2014;34:1769-90.

60. Sirajuddin A, Donnelly EF, Crabtree TP, et al. ACR Appropriateness Criteria((R)) Suspected Pulmonary Hypertension. J Am Coll Radiol 2017;14:S350-61.

61. Metter D, Tulchinsky M, Freeman LM. Current Status of Ventilation-Perfusion Scintigraphy for Suspected Pulmonary Embolism. AJR Am J Roentgenol 2017;208:489-94.

62. Bailey DL, Eslick EM, Schembri GP, et al. (68)Ga PET Ventilation and Perfusion Lung Imaging-Current Status and Future Challenges. Semin Nucl Med 2016;46:428-35.

63. Le Roux PY, Hicks RJ, Siva S, et al. PET/CT Lung Ventilation and Perfusion Scanning using Galligas and Gallium-68-MAA. Semin Nucl Med 2019;49:71-81.

64. Nicod P, Peterson K, Levine M, et al. Pulmonary angiography in severe chronic pulmonary hypertension. Ann Intern Med 1987;107:565-8.

65. Auger WR, Kerr KM, Kim NH, et al. Evaluation of patients with chronic thromboembolic pulmonary hypertension for pulmonary endarterectomy. Pulm Circ 2012;2:155-62.

66. Wang J, Prakasa K, Bomma C, et al. Comparison of novel echocardiographic parameters of right ventricular function with ejection fraction by cardiac magnetic resonance. J Am Soc Echocardiogr 2007;20:1058-64.

67. Marrone G, Mamone G, Luca A, et al. The role of $1.5 \mathrm{~T}$ cardiac MRI in the diagnosis, prognosis and management of pulmonary arterial hypertension. Int J Cardiovasc Imaging 2010;26:665-81.

68. McMurray JJ, Adamopoulos S, Anker SD, et al. ESC Guidelines for the diagnosis and treatment of acute and chronic heart failure 2012: The Task Force for the Diagnosis and Treatment of Acute and Chronic Heart Failure 2012 of the European Society of Cardiology. Developed in collaboration with the Heart Failure Association (HFA) of the ESC. Eur Heart J 2012;33:1787-847.
69. Peña E, Dennie C, Veinot J, et al. Pulmonary hypertension: how the radiologist can help. Radiographics 2012;32:9-32.

70. Peacock AJ, Vonk Noordegraaf A. Cardiac magnetic resonance imaging in pulmonary arterial hypertension. Eur Respir Rev 2013;22:526-34.

71. van Wolferen SA, Marcus JT, Boonstra A, et al. Prognostic value of right ventricular mass, volume, and function in idiopathic pulmonary arterial hypertension. Eur Heart J 2007;28:1250-7.

72. Benza R, Biederman R, Murali S, et al. Role of cardiac magnetic resonance imaging in the management of patients with pulmonary arterial hypertension. J Am Coll Cardiol 2008;52:1683-92.

73. Sanz J, Garcia-Alvarez A, Fernandez-Friera L, et al. Right ventriculo-arterial coupling in pulmonary hypertension: a magnetic resonance study. Heart 2012;98:238-43.

74. Hoeper MM, Barbera JA, Channick RN, et al. Diagnosis, assessment, and treatment of non-pulmonary arterial hypertension pulmonary hypertension. J Am Coll Cardiol 2009;54:S85-96.

75. Drazner MH, Hamilton MA, Fonarow G, et al.

Relationship between right and left-sided filling pressures in 1000 patients with advanced heart failure. J Heart Lung Transplant 1999;18:1126-32.

76. Ghio S, Gavazzi A, Campana C, et al. Independent and additive prognostic value of right ventricular systolic function and pulmonary artery pressure in patients with chronic heart failure. J Am Coll Cardiol 2001;37:183-8.

77. Kjaergaard J, Akkan D, Iversen KK, et al. Prognostic importance of pulmonary hypertension in patients with heart failure. Am J Cardiol 2007;99:1146-50.

78. Rosario LB, Stevenson LW, Solomon SD, et al. The mechanism of decrease in dynamic mitral regurgitation during heart failure treatment: importance of reduction in the regurgitant orifice size. J Am Coll Cardiol 1998;32:1819-24.

79. Hagger D, Condliffe R, Woodhouse N, et al. Ventricular mass index correlates with pulmonary artery pressure and predicts survival in suspected systemic sclerosis-associated pulmonary arterial hypertension. Rheumatology (Oxford) 2009;48:1137-42.

80. van de Veerdonk MC, Kind T, Marcus JT, et al. Progressive right ventricular dysfunction in patients with pulmonary arterial hypertension responding to therapy. J Am Coll Cardiol 2011;58:2511-9.

81. Freed BH, Gomberg-Maitland M, Chandra S, et al. Late gadolinium enhancement cardiovascular magnetic 
resonance predicts clinical worsening in patients with pulmonary hypertension. J Cardiovasc Magn Reson 2012;14:11.

82. Gan CT, Lankhaar JW, Westerhof N, et al. Noninvasively assessed pulmonary artery stiffness predicts mortality in pulmonary arterial hypertension. Chest 2007;132:1906-12.

83. Freed BH, Collins JD, Francois CJ, et al. MR and CT Imaging for the Evaluation of Pulmonary Hypertension. JACC Cardiovasc Imaging 2016;9:715-32.

84. Swift AJ, Wild JM, Nagle SK, et al. Quantitative magnetic resonance imaging of pulmonary hypertension: a practical approach to the current state of the art. J Thorac Imaging 2014;29:68-79.

85. Scalia GM, Scalia IG, Kierle R, et al. ePLAR - The echocardiographic Pulmonary to Left Atrial Ratio - A novel non-invasive parameter to differentiate pre-capillary and post-capillary pulmonary hypertension. Int J Cardiol 2016;212:379-86.

86. Greiner S, Andre F, Heimisch M, et al. Non-invasive quantification of right ventricular systolic function by echocardiography: a new semi-automated approach. Clin Res Cardiol 2013;102:229-35.

87. Gerges M, Gerges C, Lang IM. Advanced imaging tools rather than hemodynamics should be the primary approach for diagnosing, following, and managing pulmonary arterial hypertension. Can J Cardiol 2015;31:521-8.

88. Vitarelli A, Mangieri E, Terzano C, et al. Threedimensional echocardiography and 2D-3D speckletracking imaging in chronic pulmonary hypertension: diagnostic accuracy in detecting hemodynamic signs of right ventricular (RV) failure. J Am Heart Assoc 2015;4:e001584.

89. Hasselberg N, Sugahara M, Kagiyama N, et al. Right atrial strain by speckle-tracking echocardiography predicts moretality in patients with pulmonary arterial hypertension. J Am Coll Cardiol 2018;71:A1925.

90. Lau EM, Bailey DL, Bailey EA, et al. Pulmonary hypertension leads to a loss of gravity dependent redistribution of regional lung perfusion: a SPECT/CT study. Heart 2014;100:47-53.

91. Kawakami T, Kataoka M, Nakahara T, et al. Usefulness of 3D SPECT/CT fusion image in CTEPH. Int J Cardiol 2015;194:39-40.

92. Lyle M, Chang I, Lin G, et al. FDG PET positive cardiac amyloidosis. Journal of Cardiac Failure 2019;25:S41.

93. Heller GV. Practical issues regarding the incorporation of PET into a busy SPECT practice. J Nucl Cardiol 2012;19 Suppl 1:S12-8.
94. Tatebe S, Fukumoto Y, Oikawa-Wakayama M, et al. Enhanced $[18 \mathrm{~F}]$ fluorodeoxyglucose accumulation in the right ventricular free wall predicts long-term prognosis of patients with pulmonary hypertension: a preliminary observational study. Eur Heart J Cardiovasc Imaging 2014;15:666-72.

95. Ahmadi A, Ohira H, Mielniczuk LM. FDG PET imaging for identifying pulmonary hypertension and right heart failure. Curr Cardiol Rep 2015;17:555.

96. Stein PD, Chenevert TL, Fowler SE, et al. Gadoliniumenhanced magnetic resonance angiography for pulmonary embolism: a multicenter prospective study (PIOPED III). Ann Intern Med 2010;152:434-43, W142-3.

97. Ohno Y, Yoshikawa T, Kishida Y, et al. Unenhanced and Contrast-Enhanced MR Angiography and Perfusion Imaging for Suspected Pulmonary Thromboembolism. AJR Am J Roentgenol 2017;208:517-30.

98. Mukundan S, Steigner ML, Hsiao LL, et al. FerumoxytolEnhanced Magnetic Resonance Imaging in Late-Stage CKD. Am J Kidney Dis 2016;67:984-8.

99. Toth GB, Varallyay CG, Horvath A, et al. Current and potential imaging applications of ferumoxytol for magnetic resonance imaging. Kidney Int 2017;92:47-66.

100. Tsuchiya N, van Beek EJ, Ohno Y, et al. Magnetic resonance angiography for the primary diagnosis of pulmonary embolism: A review from the international workshop for pulmonary functional imaging. World $\mathrm{J}$ Radiol 2018;10:52-64.

101. García-Álvarez A, Garcia-Lunar I, Pereda D, et al. Association of myocardial T1-mapping CMR with hemodynamics and $\mathrm{RV}$ performance in pulmonary hypertension. JACC Cardiovasc Imaging 2015;8:76-82.

102. Taylor AJ, Salerno M, Dharmakumar R, et al. T1 Mapping: Basic Techniques and Clinical Applications. JACC Cardiovasc Imaging 2016;9:67-81.

103. Moon JC, Messroghli DR, Kellman P, et al. Myocardial T1 mapping and extracellular volume quantification: a Society for Cardiovascular Magnetic Resonance (SCMR) and CMR Working Group of the European Society of Cardiology consensus statement. J Cardiovasc Magn Reson 2013;15:92.

104. Shehata ML, Harouni AA, Skrok J, et al. Regional and global biventricular function in pulmonary arterial hypertension: a cardiac MR imaging study. Radiology 2013;266:114-22.

105. Reiter G, Reiter U, Kovacs G, et al. Magnetic resonancederived 3-dimensional blood flow patterns in the main pulmonary artery as a marker of pulmonary hypertension 
and a measure of elevated mean pulmonary arterial pressure. Circ Cardiovasc Imaging 2008;1:23-30.

106. Reiter U, Reiter G, Kovacs G, et al. Evaluation of elevated mean pulmonary arterial pressure based on magnetic resonance 4D velocity mapping: comparison of visualization techniques. PLoS One 2013;8:e82212.

107. Reiter G, Reiter U, Kovacs G, et al. Blood flow vortices along the main pulmonary artery measured with MR imaging for diagnosis of pulmonary hypertension. Radiology 2015;275:71-9.

108. Schäfer M, Barker AJ, Kheyfets V, et al. Helicity and Vorticity of Pulmonary Arterial Flow in Patients With Pulmonary Hypertension: Quantitative Analysis of Flow Formations. J Am Heart Assoc 2017;6:e007010.

109. Fenster BE, Browning J, Schroeder JD, et al. Vorticity is a marker of right ventricular diastolic dysfunction. Am J Physiol Heart Circ Physiol 2015;309:H1087-93.

110.Sun XG, Hansen JE, Oudiz RJ, et al. Exercise pathophysiology in patients with primary pulmonary hypertension. Circulation 2001;104:429-35.

111. Holverda S, Gan CT, Marcus JT, et al. Impaired stroke volume response to exercise in pulmonary arterial hypertension. J Am Coll Cardiol 2006;47:1732-3.

112. Nootens M, Wolfkiel CJ, Chomka EV, et al. Understanding right and left ventricular systolic function and interactions at rest and with exercise in primary pulmonary hypertension. Am J Cardiol 1995;75:374-7.

113. Spruijt OA, de Man FS, Groepenhoff H, et al. The effects of exercise on right ventricular contractility and right ventricular-arterial coupling in pulmonary hypertension. Am J Respir Crit Care Med 2015;191:1050-7.

Cite this article as: Sharma M, Burns AT, Yap K, Prior DL. The role of imaging in pulmonary hypertension. Cardiovasc Diagn Ther 2021;11(3):859-880. doi: 10.21037/cdt-20-295
114. Claessen G, La Gerche A, Dymarkowski S, et al. Pulmonary vascular and right ventricular reserve in patients with normalized resting hemodynamics after pulmonary endarterectomy. J Am Heart Assoc 2015;4:e001602.

115.Lau EMT, Vanderpool RR, Choudhary P, et al. Dobutamine stress echocardiography for the assessment of pressure-flow relationships of the pulmonary circulation. Chest 2014;146:959-66.

116. Naeije R, Vanderpool R, Dhakal BP, et al. Exerciseinduced pulmonary hypertension: physiological basis and methodological concerns. Am J Respir Crit Care Med 2013;187:576-83.

117. Baillie TJ, Sidharta S, Steele PM, et al. The predictive capabilities of a novel cardiovascular magnetic resonance derived marker of cardiopulmonary reserve on established prognostic surrogate markers in patients with pulmonary vascular disease: results of a longitudinal pilot study. J Cardiovasc Magn Reson 2017;19:3.

118. Baillie TJ, Sidharta S, Steele PM, et al. Noninvasive Assessment of Cardiopulmonary Reserve: Toward Early Detection of Pulmonary Vascular Disease. Am J Respir Crit Care Med 2017;195:398-401.

119. La Gerche A, Claessen G, Van de Bruaene A, et al. Cardiac MRI: a new gold standard for ventricular volume quantification during high-intensity exercise. Circ Cardiovasc Imaging 2013;6:329-38.

120. Lin AC, Strugnell WE, Seale H, et al. Exercise cardiac MRI-derived right ventriculo-arterial coupling ratio detects early right ventricular maladaptation in PAH. Eur Respir J 2016;48:1797-800. 